Western University

Scholarship@Western

Chemistry Publications

Chemistry Department

Spring 6-21-2016

\title{
Synthesis, properties, and antibacterial activity of polyphosphonium semi-interpenetrating networks
}

Tyler John Cuthbert

The University of Western Ontario

Tristan Harrison

Western University, tharri32@uwo.ca

Paul J. Ragogna

The University of Western Ontario

Elizabeth Gillies

Western University, egillie@uwo.ca

Follow this and additional works at: https://ir.lib.uwo.ca/chempub

Part of the Polymer Chemistry Commons

Citation of this paper:

Cuthbert, Tyler John; Harrison, Tristan; Ragogna, Paul J.; and Gillies, Elizabeth, "Synthesis, properties, and antibacterial activity of polyphosphonium semi-interpenetrating networks" (2016). Chemistry Publications. 85.

https://ir.lib.uwo.ca/chempub/85 


\section{Synthesis, properties, and antibacterial activity of}

\section{polyphosphonium semi-interpenetrating networks}

Tyler J. Cuthbert", Tristan D. Harrison ${ }^{\#}$, Paul J. Ragogna ${ }^{\#}$, and Elizabeth R. Gillies ${ }^{\# *}$

\#Department of Chemistry and Center for Advanced Materials and Biomaterials Research (CAMBR), The University of Western Ontario, 1151 Richmond St., London, Canada N6A 5B7

${ }^{\$}$ Department of Chemical and Biochemical Engineering, The University of Western Ontario, 1151

Richmond St., London, Canada N6A 5B9

\section{Table of contents entry}

Polyphosphonium semi-interpenetrating networks were prepared and studied as antibacterial surfaces to elucidate the structural aspects leading to bacterial killing.

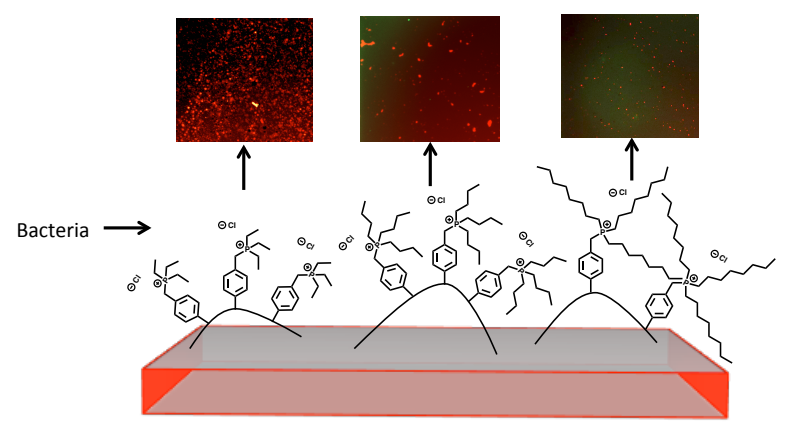




\begin{abstract}
The development of new approaches to antibacterial surfaces is of growing interest to combat the spread of harmful bacterial infections. Relative to polyammoniums, polyphosphoniums can exhibit enhanced chemical and thermal stability, but have not yet been widely explored for the preparation of antibacterial surfaces. In this work, polyphosphoniums of varying chain lengths were synthesized by reversible addition-fragmentation chain-transfer polymerization of 4-vinylbenzyl derivatives of triethyl, tributyl, and trioctylphosphonium. These polyphosphoniums were then incorporated into semiinterpenetrating networks (SIPNs) based on tetra(ethylene glycol) diacrylate (TEGDA) via a UV lightinitiated curing process. Measurements of cure percentage, gel content, water contact and angle, and surface charge density suggested that all polyphosphoniums were well integrated into the network with the exception of one formulation. The results also suggested that the triethylphosphonium system tended to undergo surface reversion. Even at relatively low loadings of 0.1 to $10 \mathrm{wt} \%$ of polyphosphonium, the surfaces exhibited high accessible surface charge. Antibacterial testing revealed high activity against $S$. aureus for the triethyl and tributylphosphonium SIPNs and lower activity for the trioctyl systems. On the other hand, antibacterial activity against $E$. coli increased with increasing alkyl chain length. This can likely be attributed to differences in the compositions of the membranes of Gram-positive versus Gram-negative bacteria. The results also indicated that while killed bacteria tended to adsorb to the surface of the triethylphosphonium system, the more hydrophobic surfaces were more effective at preventing bacterial adsorption.
\end{abstract}




\section{Introduction}

Polymer networks are 3-dimensional, insoluble high molar mass polymers comprising linear chains connected by covalent cross-links or non-covalent interactions between these chains. ${ }^{1,2}$ The ability to readily tune their properties by varying both molecular structure and the degree of cross-linking have enabled the use of polymer networks in a wide range of applications including industrial surface coatings, ${ }^{3}$ rubbers, ${ }^{4} 3 \mathrm{D}$ printed plastics, ${ }^{5,6}$ and hydrogels for drug delivery and regenerative medicine. ${ }^{7,8}$ The use of specific additives that do not constitute the backbone or primary component of the network but that enhance properties such as mechanical strength, ${ }^{9,10}$ coating adhesion, ${ }^{11}$ thermal stability, ${ }^{12}$ hydrophobicity, ${ }^{13,14}$ or introduce new functions such as self-healing, ${ }^{13,15,16}$ flame retardancy, ${ }^{17}$ or the ability to support cell growth ${ }^{18}$ is a commonly employed approach to further broaden the utility of polymer networks. Semi-interpenetrating polymer networks (SIPNs) are a special class of polymer network materials that are composed of one or more networks, and one or more linear or branched polymers that penetrate the network at the molecular scale, at least to some degree. ${ }^{19}$ In SIPNs, the linear polymer can impart functions such as conductivity, ${ }^{20}$ swellability, ${ }^{21}$ shape memory effects, ${ }^{22}$ and antibacterial activity. ${ }^{23}$

Polyelectrolyte networks and SIPNs contain charged polymers, where specific properties and functions are imparted to the network by the polyelectrolyte. For example, networks containing polysulfonates have been explored as proton exchange membranes in fuel cells. ${ }^{24}$ The incorporation of polyammoniums or polycarboxylates into hydrogels have been used to introduce $\mathrm{pH}$-responsive properties. ${ }^{25,26}$ Our group has recently explored the preparation of phosphonium polymer networks by curing with ultra-violet (UV) light. In comparison to their widely-investigated nitrogen counterparts, phosphoniums are of particular interest because they exhibit differences in charge distribution and increased chemical and thermal stability relative to ammoniums that may translate into enhanced 
properties for various applications. ${ }^{27}$ By tuning the chemical structure of the phosphonium monomer, counterion, and cross-linker, it has been possible to readily tune properties such as coating hardness, hydrophobicity, swellability, and ion exchange rate. ${ }^{28-30}$ The deposition of gold nanoclusters through ion exchange was also explored. ${ }^{31}$ To the best of our knowledge, there are only two prior reports of SIPNs incorporating polyphosphoniums. In one case, the SIPNs were used to template the synthesis of gold nanoparticles, ${ }^{32}$ and in another case for the 3 -D printing of ion-conductive networks. ${ }^{33}$

In addition to the aforementioned applications, the development of antibacterial coatings is currently of significant interest due to the increasing proliferation of antibiotic-resistant infections, and their spread through direct contact with surfaces in settings such as hospitals and food processing facilities. ${ }^{34-36}$ While many approaches involve the physical encapsulation and release of biocides such as conventional antibiotics, ${ }^{37-39}$ heavy metals, ${ }^{40}$ and quaternary ammoniums,${ }^{41}$ a more permanent immobilization approach can mitigate problems associated with the release of sub-inhibitory concentrations of biocide that can lead to resistance, environmental contamination, and the eventual depletion of the surface's bioactivity. ${ }^{42}$ Various approaches including covalent conjugation, ${ }^{43}$ controlled polymerization, ${ }^{44}$ photopolymerization, ${ }^{45}$ plasma polymerization/immobilization, ${ }^{46-48}$ and layer-by-layer assembly ${ }^{37}$ have been introduced for the grafting of antibacterial polymers on surfaces. However, many of these processes are relatively tedious or require a functionalized substrate onto which grafting is performed. In this context, UV curing of a polymer network coating is a rapid and simple method for preparing antibacterial surfaces.

Small molecule phosphonium and polyphosphonium antibacterial activity has been previously reported. ${ }^{35,49-51}$ Despite this, there are few examples of antibacterial phosphonium-based surfaces. ${ }^{52,53}$ We have recently reported antibacterial polymer network coatings prepared via the UV-initiated curing of ((3-acryloyloxypropyl)tributyl)phosphonium chloride in the presence of 
tricyclo[5.2.1.0 $\left.0^{2,6}\right]$ decanedimethanol diacrylate and a photoinitiator. ${ }^{52}$ However, a high content $(47.5$ $\mathrm{wt} \%$ ) of the phosphonium monomer was required to obtain sufficient surface charge for bacterial killing. Herein we introduce a new and alternative approach to phosphonium-containing antibacterial surfaces involving the incorporation of relatively low loadings ( 0.1 to $10 \mathrm{wt} \%$ ) of polyphosphoniums into polymer networks formed from tetra(ethylene glycol) diacrylate (TEGDA) via UV-curing, thereby forming SIPNs (Figure 1). In addition, while the previous work involved tributylphosphoniums, the current work also explores triethylphosphonium and trioctylphosphonium groups in order to elucidate their effects on antibacterial efficacy, as well as other coating properties. Through comparisons of the properties of a library of SIPNs, as well as studies of their ability to kill Escherichia coli (E. coli) and Staphylococcus aureus (S. aureus), this work provides new insights into the preparation and properties of phosphonium SIPNs and into how the composition and architecture of phosphonium coatings can influence their antibacterial efficacy.
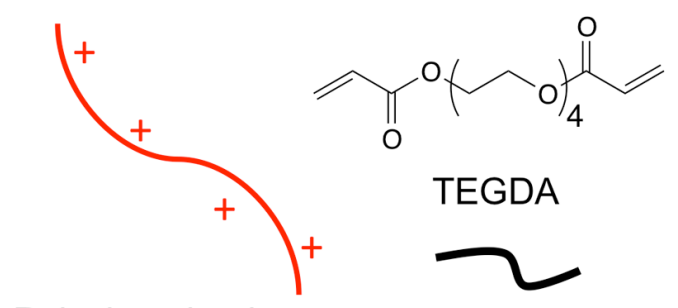

Polyphosphonium
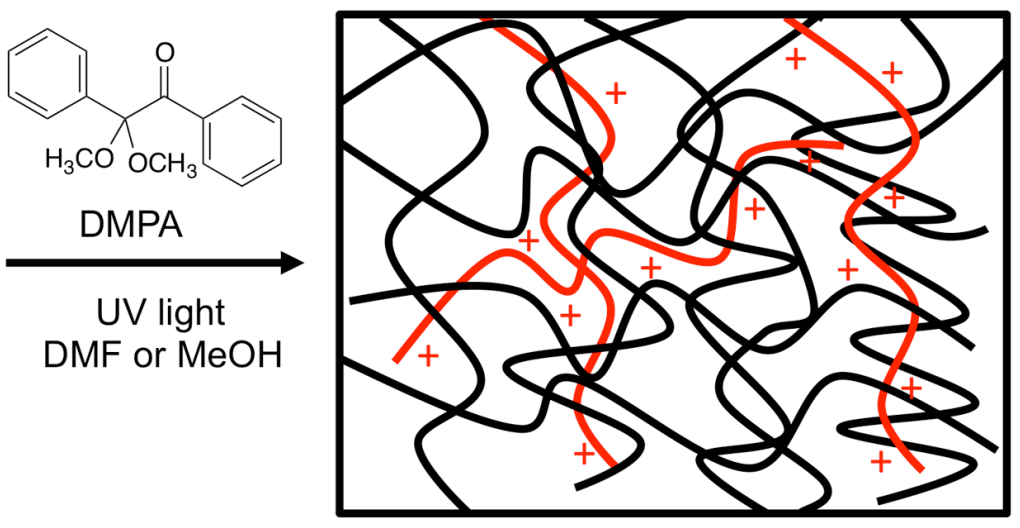

Figure 1. Schematic illustrating the incorporation of polyphosphoniums into an SIPN.

\section{Experimental}

\section{General materials and procedures}

CTA1 $^{54}$ and CTA2 $^{55}$ (Scheme 1) were synthesized according to previously published procedures. Et$\mathbf{P}, \mathbf{B u}-\mathbf{P}$, and $\mathbf{O}-\mathbf{P}$ were prepared by modifications of previously reported procedures and the details are 
included in the ESI. Solvents were purchased from Caledon Laboratory Chemicals (Georgetown, ON, Canada). Deuterated solvents were purchased from Cambridge Isotopes Laboratories (Tewskbury, MA, USA). Phosphines were supplied by Cytec Solvay (Niagara Falls, ON, Canada). VA-044 was purchased from Toronto Research Chemicals (Toronto, ON, Canada). All other chemical reagents were purchased from Sigma Aldrich (St. Louis, MO, USA). All solvents and chemicals were used as received unless otherwise noted. Nuclear Magnetic Resonance (NMR) spectroscopy was conducted on a Varian Inova $400 \mathrm{MHz}$ Spectrometer (Varian, Palo Alto, CA, USA) $\left({ }^{1} \mathrm{H} 400.09 \mathrm{MHz},{ }^{31} \mathrm{P}\left\{{ }^{1} \mathrm{H}\right\}\right.$ 161.82 MHz). All ${ }^{1} \mathrm{H}$ and ${ }^{13} \mathrm{C}\left\{{ }^{1} \mathrm{H}\right\}$ NMR spectra were referenced relative to the residual solvent peak $\left(\mathrm{CHCl}_{3}:{ }^{1} \mathrm{H} \delta=7.26,{ }^{13} \mathrm{C} \delta=77 ; \mathrm{H}_{2} \mathrm{O}:{ }^{1} \mathrm{H} \delta=4.79\right)$. All ${ }^{31} \mathrm{P}\left\{{ }^{1} \mathrm{H}\right\}$ NMR spectra were referenced using an external standard $\left(85 \% \mathrm{H}_{3} \mathrm{PO}_{4}:{ }^{31} \mathrm{P} \delta=0\right)$. Coupling constants $(J)$ are expressed in Hertz $(\mathrm{Hz})$. Fourier transform infrared (FTIR) spectroscopy was conducted using a Bruker Tensor 27 spectrometer (Bruker, Billerica, MA, USA) in attenuated total reflectance mode (ATR) using a ZnSe crystal or a Perkin Elmer FT-IR Spectrum Two Spectrometer (Waltham, MA, USA) in the universal attenuated total reflectance mode (UATR), using a diamond crystal as well as the UATR sampling accessory (part number L1050231). Differential scanning calorimetry (DSC) was completed on a DSC Q20 TA Instruments (Waters, New Castle, DE, USA) at a heating rate of $10^{\circ}$ /minute, under an $\mathrm{N}_{2}$ atmosphere, in an aluminum Tzero ${ }^{\mathrm{TM}}$ pan with approximately $5 \mathrm{mg}$ of sample. The glass transition temperature $\left(\mathrm{T}_{\mathrm{g}}\right)$ was determined from the second heating cycle. Thermogravimetric analysis (TGA) was completed on a Q600 SDT TA Instruments and analyzed using TA Universal Analysis, under an $\mathrm{N}_{2}$ atmosphere at a heating rate of $10{ }^{\circ} \mathrm{C} / \mathrm{min}$ up to $600{ }^{\circ} \mathrm{C}$ using a ceramic pan with approximately $2 \mathrm{mg}$ of sample. UVVis spectroscopy was conducted using a Varian Cary 300 Bio UV-Vis Spectrophotometer (Varian, Palo Alto, CA, USA) and quartz $1 \mathrm{~cm}$ path length cells. 


\section{General method for the polymerization of phosphonium monomers Et-P, Bu-P and O-P}

Monomer (Et-P), initiator (VA-044), and RAFT agent (CTA1) were dissolved in $\mathrm{H}_{2} \mathrm{O}$ in a round

bottom flask, and the flask was sealed with a new Suba-Seal ${ }^{\circledR}$ septum (Sigma Aldrich, St. Louis, USA) and Teflon tape. Alternatively, monomers (Bu-P, and O-P), initiator (AIBN), and RAFT agent (CTA2) were dissolved in $\mathrm{CH}_{3} \mathrm{CN}$ in a round bottom flask, and flask was sealed as above. The reaction mixture was degassed by bubbling $\mathrm{N}_{2}$ through the solution with stirring at $0{ }^{\circ} \mathrm{C}$ for 30 minutes. The reaction flask was then put directly into an oil bath at the appropriate temperature to initiate the polymerization. Et-P was polymerized at $60^{\circ} \mathrm{C}$ and $\mathbf{B u}-\mathbf{P}$ and $\mathbf{O}-\mathbf{P}$ were polymerized at $80{ }^{\circ} \mathrm{C}$. Aliquots were taken throughout the reaction to monitor the conversion by ${ }^{1} \mathrm{H}$ NMR spectroscopy, observing the decrease of the vinylic protons between 5 and $6 \mathrm{ppm}$ in comparison to the protons at $\sim 1 \mathrm{ppm}$ corresponding to the methyl groups on the phosphonium alkyl substituents that were set to a constant integration of 9. When the reaction reached $\sim 80 \%$ conversion, the reaction was removed from the oil bath, cooled to room temperature and exposed to air. The solvent was then removed in vacuo, the crude reaction mixture was redissolved ( $\mathbf{P}(\mathbf{E t}-\mathbf{P})$ in isopropanol, $\mathbf{P}(\mathbf{B u}-\mathbf{P})$ in $\left.\mathrm{CH}_{2} \mathrm{Cl}_{2}\right)$ and then the polymer was precipitated in an anti-solvent (Et-P and Bu-P in THF), collected by vacuum filtration, and dried in vacuo. P(O-P) was purified by dialsysis against $\left(\mathrm{CH}_{3}\right)_{2} \mathrm{CO}$ with a regenerated cellulose membrane (Spectra/Por $\left.{ }^{\circledR} \mathrm{RC}\right)$ with molecular weight cutoff (MWCO) of $35 \mathrm{~kg} / \mathrm{mol}$.

\section{P(Et-P)-10k}

Monomer $=\mathbf{E t}-\mathbf{P}(1.50 \mathrm{~g}, 5.54 \mathrm{mmol}) ;$ Initiator $=$ VA-044 $(0.010 \mathrm{~g}, 0.031 \mathrm{mmol}) ;$ Solvent $=\mathrm{H}_{2} \mathrm{O}(30$ $\mathrm{mL})$; RAFT agent $=$ CTA1 $(0.037 \mathrm{~g}, 0.14 \mathrm{mmol})$. The polymer was purified by precipitation from isopropanol into THF. Yield $=0.66 \mathrm{~g}, 55 \% ; \mathrm{M}_{\mathrm{n}}$ based on ${ }^{1} \mathrm{H}$ NMR spectroscopy $=10.6 \mathrm{~kg} / \mathrm{mol} ; \mathrm{M}_{\mathrm{n}}$ based on UV-vis spectroscopy $=13.8 \pm 0.4 \mathrm{~kg} / \mathrm{mol} ;{ }^{1} \mathrm{H}$ NMR $\left(\mathrm{D}_{2} \mathrm{O}\right): \delta=7.03$ (broad, Ar-H, ortho to 
$\mathrm{CH}_{2}-\mathrm{P}$ ), 6.46 (broad, Ar-H, meta to $\mathrm{CH}_{2}-\mathrm{P}$ ), 3.52 (broad, Ar- $\mathrm{CH}_{2}-\mathrm{P}$ ), 1.96 (broad, $\mathrm{P}-\mathrm{C}_{2}-\mathrm{CH}_{3}$, backbone C-H), 1.37 (broad, backbone $\left.\mathrm{CH}_{2}\right), 0.87$ (broad, $\left.\mathrm{P}-\mathrm{CH}_{2}-\mathrm{CH}_{3}\right) ;{ }^{31} \mathrm{P}\{1 \mathrm{H}\} \mathrm{NMR}\left(\mathrm{CDCl}_{3}\right): \delta=$ $37.6(\mathrm{~s}) ; \mathrm{T}_{\mathrm{o}}=386{ }^{\circ} \mathrm{C} ; \mathrm{T}_{\mathrm{g}}=224^{\circ} \mathrm{C}$.

\section{P(Et-P)-40k}

Monomer $=\mathbf{E t}-\mathbf{P}(1.51 \mathrm{~g}, 5.58 \mathrm{mmol})$; Initiator = VA-044 $(3.0 \mathrm{mg}, 9.3 \mu \mathrm{mol})$; Solvent $=\mathrm{H}_{2} \mathrm{O}(30 \mathrm{~mL})$; RAFT agent $=$ CTA1 $(8.0 \mathrm{mg}, 0.032 \mathrm{mmol})$. The polymer was purified by precipitation from isopropanol into THF. Yield $=1.39 \mathrm{~g}, 92 \% . \mathrm{M}_{\mathrm{n}}$ based on ${ }^{1} \mathrm{H}$ NMR spectroscopy $=42.5 \mathrm{~kg} / \mathrm{mol} ; \mathrm{M}_{\mathrm{n}}$ based on UV-vis spectroscopy $=40.6 \pm 1.1 \mathrm{~kg} / \mathrm{mol} .{ }^{1} \mathrm{H}$ NMR $\left(\mathrm{D}_{2} \mathrm{O}\right): \delta=7.21$ (broad, Ar-H, ortho to $\mathrm{CH}_{2}-\mathrm{P}$ ), 6.55 (broad, Ar-H, meta to $\mathrm{CH}_{2}-\mathrm{P}$ ), 3.55 (broad, Ar- $\mathrm{CH}_{2}-\mathrm{P}$ ), 2.14 (broad, $\mathrm{P}-\mathrm{CH}_{2}-\mathrm{CH}_{3}$, backbone C-H), 1.57 (broad, backbone $\left.\mathrm{CH}_{2}\right), 1.06$ (broad, $\left.\mathrm{P}-\mathrm{CH}_{2}-\mathrm{CH}_{3}\right) ;{ }^{31} \mathrm{P}\left\{{ }^{1} \mathrm{H}\right\} \mathrm{NMR}\left(\mathrm{D}_{2} \mathrm{O}\right): 37.0 ; \mathrm{T}_{\mathrm{o}}$ $=389 ; \mathrm{T}_{\mathrm{g}}=220^{\circ} \mathrm{C}$

\section{P(Bu-P)-10k}

Monomer $=\mathbf{B u}-\mathbf{P}(0.913 \mathrm{~g}, 2.57 \mathrm{mmol})$; Initiator $=\mathbf{A I B N}(3.0 \mathrm{mg}, 0.018 \mathrm{mmol})$; Solvent $=\mathrm{CH}_{3} \mathrm{CN}$ $(3.6 \mathrm{~mL})$; RAFT agent $=$ CTA2 $(0.021 \mathrm{~g}, 0.057 \mathrm{mmol})$. The polymer was purified by precipitation from $\mathrm{CH}_{2} \mathrm{Cl}_{2}$ into THF. Yield $=0.528 \mathrm{~g}, 58 \%$. $\mathrm{M}_{\mathrm{n}}$ based on ${ }^{1} \mathrm{H}$ NMR spectroscopy $=10.6 \mathrm{~kg} / \mathrm{mol} ; \mathrm{M}_{\mathrm{n}}$ based on UV-vis spectroscopy $=9.9 \pm 2.9 \mathrm{~kg} / \mathrm{mol} .{ }^{1} \mathrm{H} \mathrm{NMR}\left(\mathrm{CDCl}_{3}\right): \delta=7.49$ (broad, Ar-H, ortho to $\mathrm{CH}_{2}-\mathrm{P}$ ), 6.51 (broad, Ar-H, meta to $\mathrm{CH}_{2}-\mathrm{P}$ ), 4.36 (broad, Ar- $\underline{\mathrm{H}}_{2}-\mathrm{P}$ ), 2.40 (broad, $\mathrm{P}-\mathrm{CH}_{2}-\left(\mathrm{CH}_{2}\right)_{2}-\mathrm{CH}_{3}$ and backbone $\mathrm{CH}$ ), 1.40 (broad, $\mathrm{P}-\mathrm{CH}_{2}-\left(\mathrm{CH}_{2}\right)_{2}-\mathrm{CH}_{3}$ and backbone $\left.\mathrm{CH}_{2}\right), 0.85$ (broad, $\left.\mathrm{P}-\left(\mathrm{CH}_{2}\right)_{3}-\mathrm{CH}_{3}\right)$; ${ }^{31} \mathrm{P}\left\{{ }^{1} \mathrm{H}\right\}$ NMR $\left(161.82 \mathrm{MHz}, \mathrm{CDCl}_{3}\right): \delta=31.3 ; \mathrm{T}_{\mathrm{o}}=363{ }^{\circ} \mathrm{C} ; \mathrm{T}_{\mathrm{g}}=147{ }^{\circ} \mathrm{C}$

\section{P(Bu-P)-40k}


Monomer $=\mathbf{B u}-\mathbf{P}(0.756 \mathrm{~g}, 2.13 \mathrm{mmol})$; Initiator $=\mathbf{A I B N}(0.8 \mathrm{mg}, 5 \mu \mathrm{mol})$; Solvent $=\mathrm{CH}_{3} \mathrm{CN}(3.00$ $\mathrm{mL})$; RAFT agent $=$ CTA2 $(5.0 \mathrm{mg}, 0.014 \mathrm{mmol})$. The polymer was purified by precipitation from $\mathrm{CH}_{2} \mathrm{Cl}_{2}$ into THF. Yield $=0.416 \mathrm{~g}, 55 \% . \mathrm{M}_{\mathrm{n}}$ based on ${ }^{1} \mathrm{H}$ NMR spectroscopy $=41.6 \mathrm{~kg} / \mathrm{mol} . \mathrm{M}_{\mathrm{n}}$ based on UV-vis spectroscopy $=41.6 \pm 1.1 \mathrm{~kg} / \mathrm{mol} ;{ }^{1} \mathrm{H}$ NMR $\left(\mathrm{CDCl}_{3}\right): \delta=7.36$ (broad, Ar-H, ortho to $\mathrm{CH}_{2}-$ P), 6.36 (broad, Ar-H, meta to $\left.\mathrm{CH}_{2}-\mathrm{P}\right), 4.36$ (broad, $\left.\mathrm{Ar}-\mathrm{CH}_{2}-\mathrm{P}\right), 2.54-2.38$ (broad m, P-C $\underline{\mathrm{H}}_{2}-\left(\mathrm{CH}_{2}\right)_{2}-$ $\mathrm{CH}_{3}$ and backbone $\mathrm{CH}$ ), 1.40 (broad, $\mathrm{P}-\mathrm{CH}_{2}-\left(\mathrm{C}_{2}\right)_{2}-\mathrm{CH}_{3}$ and backbone $\left.\mathrm{CH}_{2}\right), 0.85$ (broad, $\mathrm{P}_{-} \mathrm{CH}_{2}-$ $\left.\left(\mathrm{CH}_{2}\right)_{2}-\underline{\mathrm{CH}}_{3}\right) ;{ }^{31} \mathrm{P}\left\{{ }^{1} \mathrm{H}\right\} \operatorname{NMR}\left(\mathrm{CDCl}_{3}\right): \delta=31.3 ; \mathrm{T}_{\mathrm{o}}=363{ }^{\circ} \mathrm{C} ; \mathrm{T}_{\mathrm{g}}=169^{\circ} \mathrm{C}$

\section{$\mathbf{P}(\mathbf{O}-\mathrm{P})-10 \mathrm{k}$}

Monomer $=\mathbf{O}-\mathbf{P}(0.821 \mathrm{~g}, 1.56 \mathrm{mmol})$; Initiator $=\mathbf{A I B N}(4.0 \mathrm{mg}, 0.024 \mathrm{mmol})$; Solvent $=\mathrm{CH}_{3} \mathrm{CN}$ $(3.28 \mathrm{~mL})$; RAFT agent $=$ CTA2 $(2.3 \mathrm{mg}, 0.063 \mathrm{mmol})$; The polymer was purified by dialysis. Yield $=$ $0.295 \mathrm{~g}, 36 \%$. $\mathrm{M}_{\mathrm{n}}$ based on ${ }^{1} \mathrm{H}$ NMR spectroscopy $=10.5 \mathrm{~kg} / \mathrm{mol}$. $\mathrm{M}_{\mathrm{n}}$ based on UV-vis spectroscopy $=$ $8.4 \pm 0.1 \mathrm{~kg} / \mathrm{mol} ;{ }^{1} \mathrm{H}$ NMR $\left(\mathrm{CDCl}_{3}\right): \delta=7.50$ (broad, Ar-H, ortho to $\left.\mathrm{CH}_{2}-\mathrm{P}\right), 6.51$ (broad, Ar-H, meta to $\mathrm{CH}_{2}-\mathrm{P}$ ), 4.36 (broad s, $\left.\mathrm{Ar}-\mathrm{CH}_{2}-\mathrm{P}\right), 2.40$ (broad, $\mathrm{P}-\mathrm{C}_{2}-\left(\mathrm{CH}_{2}\right)_{4}-\mathrm{CH}_{3}$ and backbone $\mathrm{CH}$ ), 1.40 (broad, P- $\mathrm{CH}_{2}-\left(\mathrm{C}_{2}\right)_{6}-\mathrm{CH}_{3}$ and backbone $\left.\mathrm{CH}_{2}\right), 0.85$ (broad, $\left.\mathrm{P}-\left(\mathrm{CH}_{2}\right)_{7}-\mathrm{CH}_{3}\right) ;{ }^{31} \mathrm{P}\left\{{ }^{1} \mathrm{H}\right\} \mathrm{NMR}\left(\mathrm{CDCl}_{3}\right): \delta=$ $31.8 ; \mathrm{T}_{\mathrm{o}}=345^{\circ} \mathrm{C} ; \mathrm{T}_{\mathrm{g}}=81^{\circ} \mathrm{C}$.

\section{$\mathbf{P}(\mathbf{O}-\mathrm{P})-40 \mathrm{k}$}

Monomer $=\mathbf{O}-\mathbf{P}(1.003 \mathrm{~g}, 1.916 \mathrm{mmol})$; Initiator $=\mathbf{A I B N}(1.0 \mathrm{mg}, 6 \mu \mathrm{mol})$; Solvent $=\mathrm{CH}_{3} \mathrm{CN}(4.00$ $\mathrm{mL})$; RAFT agent $=$ CTA2 (7.0 mg, $0.019 \mathrm{mmol})$; Yield $=0.230 \mathrm{~g}, 23 \%$; $\mathrm{M}_{\mathrm{n}}$ based on ${ }^{1} \mathrm{H}$ NMR spectroscopy $=40 \mathrm{~kg} / \mathrm{mol} ; \mathrm{M}_{\mathrm{n}}$ based on UV-vis spectroscopy $=31.7 \pm 1.3 \mathrm{~kg} / \mathrm{mol} ;{ }^{1} \mathrm{H} \mathrm{NMR}\left(\mathrm{CDCl}_{3}\right): \delta$ $=7.30$ (broad, Ar-H, ortho to $\left.\mathrm{CH}_{2}-\mathrm{P}\right), 6.30$ (broad, $\mathrm{Ar}-\mathrm{H}$, meta to $\left.\mathrm{CH}_{2}-\mathrm{P}\right), 4.37$ (broad, $\mathrm{Ar}^{-} \mathrm{CH}_{2}-\mathrm{P}$ ), 2.36 
(broad, P- $\underline{\mathrm{H}}_{2}-\left(\mathrm{CH}_{2}\right)_{6}-\mathrm{CH}_{3}$ and backbone $\left.\mathrm{CH}\right), 1.45-1.10$ (broad m, $\mathrm{P}-\mathrm{CH}_{2}-\left(\mathrm{C}_{2}\right)_{6}-\mathrm{CH}_{3}$ and backbone $\left.\mathrm{CH}_{2}\right), 0.76\left(\right.$ broad s, $\left.\mathrm{P}-\left(\mathrm{CH}_{2}\right)_{7}-\mathrm{CH}_{3}\right) ;{ }^{31} \mathrm{P}\left\{{ }^{1} \mathrm{H}\right\} \operatorname{NMR}(\mathrm{CDCl} 3): \delta=31.0 ; \mathrm{T}_{\mathrm{o}}=353{ }^{\circ} \mathrm{C} ; \mathrm{T}_{\mathrm{g}}=94{ }^{\circ} \mathrm{C}$.

\section{Determination of $M_{n}$ by end-group analysis using UV-vis spectroscopy}

Calibration curves were prepared using CTA1 (in $\mathrm{H}_{2} \mathrm{O}$ ) and CTA2 (in $\mathrm{CH}_{3} \mathrm{CN}$ ) over concentration ranges of $1 \times 10^{-4}$ to $8 \times 10^{-5} \mathrm{M}$ and $1 \times 10^{-3}$ to $1 \times 10^{-4} \mathrm{M}$ respectively to determine the extinction coefficients $(\varepsilon)$ of the polymer end-groups. These were determined to be $12279 \mathrm{M}^{-1} \mathrm{~cm}^{-1}$ and $1150 \mathrm{M}^{-1}$ $\mathrm{cm}^{-1}$ for CTA1 and CTA2 respectively at $310 \mathrm{~nm}$. Purified linear polymers were thoroughly dried in a vacuum oven at $50{ }^{\circ} \mathrm{C}$ overnight before testing. A mass (m) of polymer $(\sim 1 \mathrm{mg})$ was accurately weighed on an analytical balance, and then dissolved in solvent (CTA1 in $\mathrm{H}_{2} \mathrm{O}$; CTA2 in $\mathrm{CH}_{3} \mathrm{CN}$ ) in a volumetric flask to a volume (V) of $25 \mathrm{~mL}$. The absorbance (A) of the solution at $310 \mathrm{~nm}$ was measured and the concentration (c) in $\mathrm{mol} / \mathrm{L}$ was calculated using $\mathrm{A}=\varepsilon \mathrm{bc}$ where $\mathrm{b}$ is the path length in $\mathrm{cm}$. After determining $\mathrm{c}, \mathrm{M}_{\mathrm{n}}$ was calculated as $\mathrm{M}_{\mathrm{n}}=\mathrm{m} /(\mathrm{cV})$. Each polymer was measured in triplicate and the results are reported as the mean \pm standard deviation.

\section{Preparation of polyphosphonium SIPNs}

Polyphosphonium, TEGDA, and 2,2-dimethoxy-2-phenylacetophenone (DMPA) were combined in the ratios indicated in Table 2 and diluted to $50 \mathrm{wt} \%$ in either methanol (P(Et-P)) or $N, N$ dimethylformamide (DMF) (P(Bu-P) and $\mathbf{P}(\mathbf{O}-\mathbf{P})$ ). $80 \mu \mathrm{L}$ of the resulting solution was deposited on a clean glass slide. Using $\sim 170 \mu \mathrm{m}$ thick electrical tape as a spacer to define the SIPN thickness, a second glass slide was then placed on top. The slides were passed 5 times at the slowest speed $(\sim 0.06 \mathrm{~m} / \mathrm{s})$ through a modified UV-curing system from UV Process Supply Inc. (Chicago, IL, USA) equipped with a Mercury Bulb with an energy and power density of UVA $\left(1784 \mathrm{~mJ} / \mathrm{cm}^{2}, 192 \mathrm{~mW} / \mathrm{cm}^{2}\right), \mathrm{UVB}(1647$ 


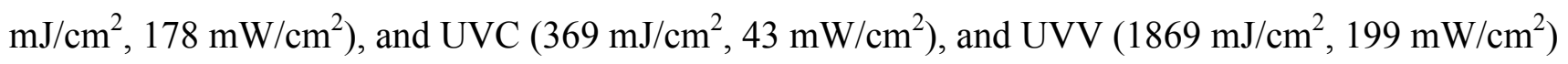
determined by a PP2-H-U Power Puck II purchased from EIT Instrument Markets (Sterling, VA, USA). Post irradiation, the glass slides were separated and the resulting material was dried overnight in a vacuum oven at $50^{\circ} \mathrm{C}$. This process resulted in SIPNs with a thickness of $\sim 150 \mu \mathrm{m}$ as measured by a micrometer.

\section{Measurement of cure percentage}

ATR-FTIR spectra were obtained before curing and for freshly prepared SIPNs after drying overnight in a vacuum oven at $50{ }^{\circ} \mathrm{C}$ to remove solvent. The peak corresponding to $\mathrm{C}=\mathrm{O}\left(1720 \mathrm{~cm}^{-1}\right)$ was used as an internal standard as its intensity does not change upon curing. The intensity of the $\mathrm{C}=\mathrm{C}$ peak $(810$ $\mathrm{cm}^{-1}$ ) was compared to that of the internal standard before curing and after curing and the cure percentage was calculated as the percent decrease in the relative intensity of the $\mathrm{C}=\mathrm{C}$ peak, with $100 \%$ corresponding to zero $\mathrm{C}=\mathrm{C}$ functionality remaining. Each $\mathrm{SIPN}$ was measured in triplicate and the results are reported as the mean \pm standard deviation.

\section{Measurement of gel content}

SIPNs from the cure percentage analysis were used to calculate gel content. The SIPN was accurately weighed and then immersed in excess $(\sim 10 \mathrm{~mL})$ of either methanol for $(\mathbf{P}(\mathbf{P}-\mathbf{E t}))$, or $\mathrm{CH}_{3} \mathrm{CN}$ for $(\mathbf{P}(\mathbf{B u}-\mathbf{P}))$ and $(\mathbf{P}(\mathbf{O}-\mathbf{P}))$ for 16 hours. The solvent was removed and the SIPN was dried in a vacuum oven at $50{ }^{\circ} \mathrm{C}$ overnight, then reweighed. The $\%$ mass remaining relative to the initial mass was determined to be the gel content. All samples were measured in triplicate and the results are reported as the mean \pm standard deviation. 


\section{Measurement of the water contact angle}

After incubation in solvent (as described above for the measurement of gel content) and drying, the SIPNs were placed on the stage of a Kruss DSA100 Drop Shape Analyzer (KRÜSS GmbH, Hamburg, Germany). Values were determined after one minute of droplet incubation on the surface. A static drop shape analyzer was used to determine the water contact angle on the surface. Each SIPN was measured in triplicate and the results are reported as the mean \pm standard deviation.

\section{Charge density determination}

This procedure was based on the previously reported protocol. ${ }^{56}$ After incubation in solvent (as described above for the measurement of gel content) and drying, the SIPNs $\left(2.25 \mathrm{~cm}^{2}\right)$ were immersed in $10 \mathrm{~mL}$ of a $1 \% \mathrm{w} / \mathrm{v}$ aqueous sodium fluorescein solution overnight. The resulting films were washed with water, and then immersed in $10 \mathrm{~mL}$ of a $0.1 \% \mathrm{v} / \mathrm{v}$ aqueous cetyl trimethyl ammonium chloride solution overnight. The surface was then removed and $10 \mathrm{mM}, \mathrm{pH} 8$ phosphate buffer was added and the absorbance of the solution at $501 \mathrm{~nm}$ was measured. The concentration of accessible charges on the surface was then determined based on the extinction coefficient of fluorescein $\left(\varepsilon=77,000 \mathrm{M}^{-1} \mathrm{~cm}^{-1}\right)$, assuming that each molecule of fluorescein binds to one accessible cation. Each SIPN was measured in triplicate and the results are reported as the mean \pm standard deviation.

\section{Measurement of mass swelling ratio in water}

After incubation in solvent (as described above for the measurement of gel content) and drying, the SIPNs were weighed, and then swelled in deionized water for 24 hours. The SIPNs were then removed from the water, excess water was removed with a Kimwipe, and the SIPN was weighed. The mass swelling \% was determined as (final mass-initial mass/initial mass)x100\%. This experiment was 
performed in triplicate for SIPNs P(Et-P)-10k (10\%), P(Bu-P)-10k (10\%), and P(O-P)-10k (10\%) and the error on the measurement was reported as the standard deviation.

\section{Determination of surface phosphorus content over time}

After incubation in solvent (as described above for the measurement of gel content) and drying, the SIPNs were either measured freshly prepared (within $24 \mathrm{~h}$ ) or after 8 months under an air atmosphere at ambient temperature. Scanning electron microscopy with energy dispersive X-ray spectroscopy (SEM-EDX) was conducted using a Hitachi S-3400N microscope with an INCA EDX attachment and software, and all surfaces were sputter coated with $5 \mathrm{~nm}$ of osmium prior to analysis. This experiment was performed for SIPNs P(Et-P)-10k (10\%), P(Bu-P)-10k (10\%), and P(O-P)-10k (10\%).

\section{Dynamic contact antibacterial test}

This procedure was based on ASTM E2149 13a. ${ }^{57}$ SIPNs were prepared for testing by first ensuring the removal of any potentially leachable biocide. Each SIPN was immersed in solvent (P(Et-P) in $\mathrm{H}_{2} \mathrm{O}$, $\mathbf{P}(\mathbf{B u}-\mathbf{P})$ in $\mathrm{CH}_{3} \mathrm{CN}, \mathbf{P}(\mathbf{O}-\mathbf{P})$ in $\left.\mathrm{CH}_{3} \mathrm{CN}\right)$ with three changes of solvent over a period of $24 \mathrm{~h}$. UV-vis spectroscopy of the washes indicated that no further components were released into solution after this protocol. The SIPNs were then dried in vacuo at $50{ }^{\circ} \mathrm{C}$ overnight. They were then ground using a mortar and pestle with $95 \%$ ethanol (5 drops) until solvent evaporated and a dry fine powder was obtained. The resulting solid was completely dried in a vacuum oven at $50{ }^{\circ} \mathrm{C}$ overnight and then used immediately for testing. A loop of precultured E. coli (ATCC 29425) or S. aureus (ATCC 6538) was freshly cultured in Lysogeny broth (LB) (VWR International, Mississauga, Canada) for 18 - 24 hours at $37^{\circ} \mathrm{C}$ ( $75 \%$ humidity) in a shaker at $175 \mathrm{rpm}$. The resulting suspension was centrifuged for 10 minutes, decanted, and resuspended in $0.3 \mathrm{mM}, \mathrm{pH} 7, \mathrm{KH}_{2} \mathrm{PO}_{4}$ buffer. This was repeated twice. The resulting 
pelletized bacteria was suspended in $0.3 \mathrm{mM} \mathrm{KH}_{2} \mathrm{PO}_{4}$ and diluted to concentrations of $10^{8} \mathrm{CFU} / \mathrm{mL}$ of S. aureus (optical density $=0.3$ at $600 \mathrm{~nm}$ ) and $10^{7} \mathrm{CFU} / \mathrm{mL}$ of $E$. coli (optical density $=0.2$ at $600 \mathrm{~nm}$ ) and as determined by optical density calibrations for each strain. The suspensions were each further diluted 100 -fold (to $10^{6} \mathrm{CFU} / \mathrm{mL}$ for $S$. aureus and $10^{5} \mathrm{CFU} / \mathrm{mL}$ of E. coli) in $0.3 \mathrm{mM} \mathrm{KH}_{2} \mathrm{PO}_{4}$ and then $100 \mu \mathrm{L}$ of this suspension was added to a sterilized centrifuge tube containing $2.0 \mathrm{mg}$ of SIPN (prepared as described above). The resulting suspensions were then incubated at room temperature with shaking at $60 \mathrm{rpm}$ on a wrist action shaker for 1 hour. Then, $900 \mu \mathrm{L}$ of $0.3 \mathrm{mM} \mathrm{KH}_{2} \mathrm{PO}_{4}$ buffer was added to each suspension, diluting the suspension to $10^{5} \mathrm{CFU} / \mathrm{mL}$ for $S$. aureus and $10^{4} \mathrm{CFU} / \mathrm{mL}$ of $E$. coli. Each suspension was further diluted 10 -fold, and $0.100 \mathrm{~mL}$ of this suspension $\left(10^{3} \mathrm{CFU}\right.$ of $S$. aureus and $10^{2} \mathrm{CFU}$ of E. coli) were pour plated using tryptic soy agar, and incubated for 24 hours at $37{ }^{\circ} \mathrm{C}$ ( $75 \%$ humidity). CFUs were then counted and the results were compared with those of the control samples that were not exposed to any polymer. Each SIPN was measured in triplicate and the results are reported as the mean \pm standard deviation. Statistical analyses (ANOVA followed by Tukey's test) were performed using the software Excel.

\section{LIVE/DEAD ${ }^{\mathrm{TM}}$ BacLight bacterial viability assay}

A suspension of S. aureus in $0.9 \%$ saline at a concentration of $10^{7} \mathrm{CFU} / \mathrm{mL}$ was prepared as described above. $1 \mathrm{~mL}$ of this suspension was placed on each $2.25 \mathrm{~cm}^{2}$ SIPN coating (prepared on an a pristine glass slide and sterilized with ethanol). The control surface was a pristine glass slide, washed with ethanol and dried. The surfaces were placed in a petri dish, the dish was sealed with parafilm, and the samples were incubated for 24 hours at $37^{\circ} \mathrm{C}$ at $75 \%$ humidity. The surfaces were then gently washed with $10 \mathrm{~mL}$ of distilled water, then incubated with a mixture of the LIVE/DEAD ${ }^{\mathrm{TM}}$ BacLight bacterial viability assay dyes (SYTO 9 and propidium iodide, Life Technologies, Burlington, Canada) for 30 
minutes in the dark according to the manufacturer's directions. The surfaces were then gently washed with deionized water and treated with Prolong Antifade mounting reagent (ThermoFisher Scientific, Massachusetts, USA) and covered with a slip cover. The prepared surfaces were then imaged by laser fluorescence microscopy using an Upright Zeiss Axioimager Z1 fluorescence microscope (Zeiss, Oberkochen, Germany) (Laser $488 \mathrm{~nm}$ for the SYTO 9 with a pass filter of 505-530 nm and a laser at $543 \mathrm{~nm}$ for the propidium iodide with a pass filter of $615 \mathrm{~nm}$, magnification $40 \times$ ). All the images were obtained and refined with the ZEN software. Each sample was tested in triplicate.

\section{Results and discussion}

\section{Synthesis of polyphosphoniums}

First the requisite phosphonium monomers were prepared. Triethyl, tributyl, and trioctylphosphine were selected as starting materials to investigate the effects of alkyl chain length and hydrophobicity on the properties of the materials. 4-Vinylbenzyl polymerizable groups were chosen because they are relatively stable during storage, yet readily undergo controlled free radical polymerization. ${ }^{58,59}$ The monomers Et-P, Bu-P, and O-P were synthesized by the reaction of phosphine with 4-vinylbenzyl chloride at $80^{\circ} \mathrm{C}$ in $\mathrm{CH}_{3} \mathrm{CN}$ (Scheme 1). Reversible addition-fragmentation chain-transfer (RAFT) was selected as a controlled method for the polymerization, because it has been previously demonstrated by our group and others, to afford controlled polymerization of vinyl phosphonium monomers. ${ }^{60,61}$ The presence of the RAFT agent at the polymer terminus following polymerization also provides a possibility for covalent attachment of the polyphosphoniums to the network during the UV-initiated free radical curing process, which is desirable for preventing undesired leaching of biocidal polymers from the resulting materials. Et-P was polymerized in water using sodium 2(((butylthio)carbonothioyl)thio)-2-methylpropanoate (CTA1) ${ }^{54}$ as the RAFT agent and 2,2'-azobis[2- 
(2-imidazolin-2-yl)propane]dihydrochloride (VA-044) as the initiator to afford P(Et-P). Bu-P and O-P were polymerized in $\mathrm{CH}_{3} \mathrm{CN}$ using (((dodecylthio)carbonothioyl)thio)-2-methylpropionic acid (CTA2) $^{55}$ as the RAFT agent and azobisisobutyronitrile (AIBN) as the initiator to afford $\mathbf{P}(\mathbf{B u}-\mathbf{P})$ and $\mathbf{P}(\mathbf{O}-\mathbf{P})$. The monomer to RAFT agent stoichiometry was adjusted to target polymers with number average molar masses $\left(\mathrm{M}_{\mathrm{n}}\right)$ of either $10 \mathrm{~kg} / \mathrm{mol}$ or $40 \mathrm{~kg} / \mathrm{mol}$ at $80 \%$ monomer conversion in order to study the effects of different polymer chain length incorporation into the networks and antibacterial activities of the resulting coatings. The concentrations of the polymerizations were chosen to ensure there was no visible increase in viscosity or phase separation during the reaction that would hinder the polymerization.

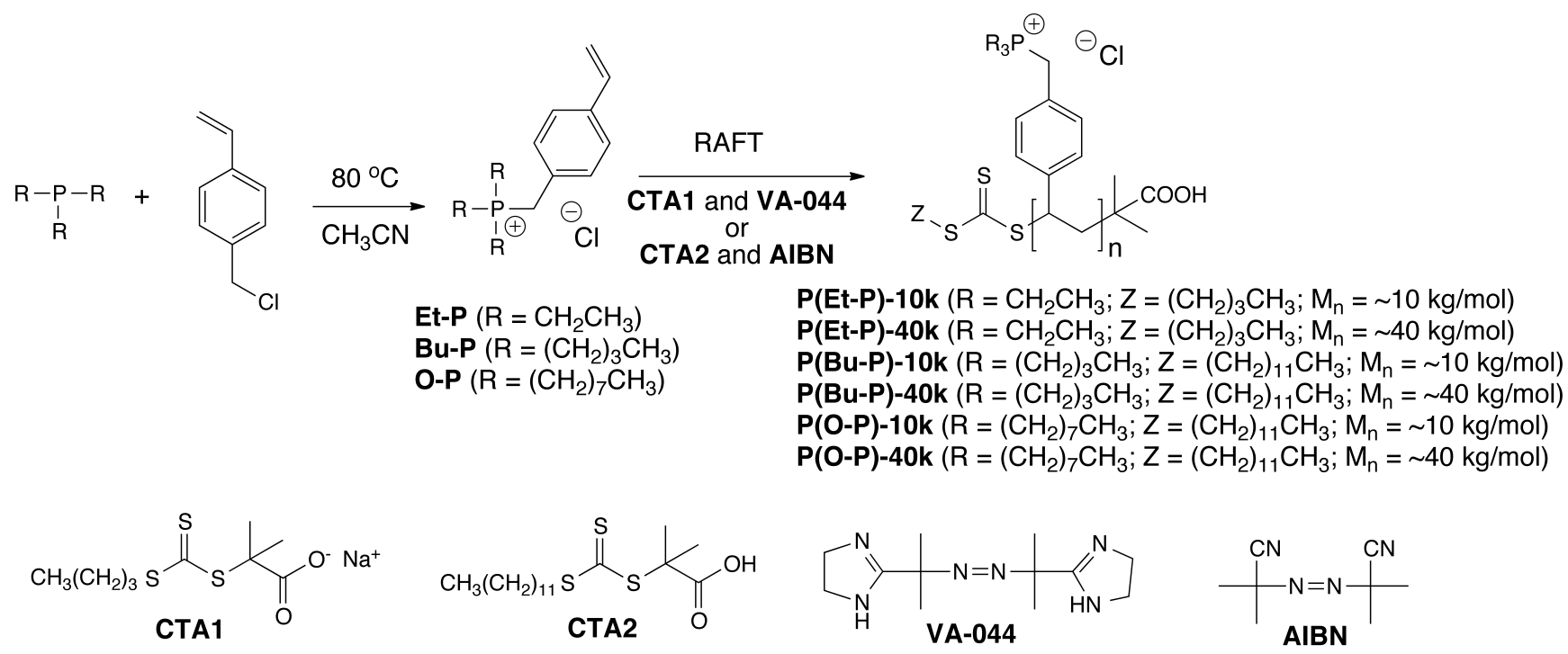

Scheme 1. Synthesis of phosphonium monomers and polyphosphoniums.

The polymerization reactions were monitored by ${ }^{1} \mathrm{H}$ NMR spectroscopy based on the disappearance of peaks corresponding to the vinylic hydrogens relative to the peaks corresponding to the terminal methyl group on the alkyl chains of the phosphonium monomer and polymer, whose total integration remained constant in the monomer and polymer (Figure 2). The polymerizations were 
stopped at $\sim 80 \%$ conversion as continued radical generation after the monomer is fully converted can lead to side reactions and cleavage of the RAFT agent from the polymer terminus. ${ }^{62}$ Table 1 shows the $\mathrm{M}_{\mathrm{n}}$ calculated for the polymers based on the monomer conversion measured by ${ }^{1} \mathrm{H}$ NMR spectroscopy. $\mathbf{P ( E t - P )}$ and $\mathbf{P ( B u - P )}$ were purified by precipitation in tetrahydrofuran (THF) from $\mathrm{CH}_{2} \mathrm{Cl}_{2} \cdot \mathbf{P}(\mathbf{O}-\mathbf{P})$ was purified by dialysis against acetone as it was not possible to selectively precipitate the polymer. The structures of the purified polymers were confirmed by ${ }^{1} \mathrm{H}$ and ${ }^{31} \mathrm{P}\left\{{ }^{1} \mathrm{H}\right\}$ NMR spectroscopy (ESI). It was not possible to confirm the molar mass characteristics of the polymers by the standard size exclusion chromatography due to interactions of these polyelectrolytes with the columns, as previously reported by our group and others. ${ }^{60,61}$ Therefore, to corroborate the expected molar masses, UV-visible spectroscopy was used to perform end group analysis based on the RAFT agent. ${ }^{63}$ As shown in Table 1, these calculated values were in good agreement with those determined based on monomer conversion by NMR spectroscopy. The thermal properties of the polymers were measured by TGA and DSC. As shown in Table 1 , all of the polymers were stable up to $345^{\circ} \mathrm{C}$ or higher. The $\mathrm{T}_{\mathrm{g}} \mathrm{s}$ of the polymers were found to decrease with increasing alkyl chain length with P(Et-P)-10k and 40k having $T_{\mathrm{g}} \mathrm{S}$ of 219 and $215^{\circ} \mathrm{C}$ respectively, $\mathbf{P}(\mathbf{B u}-\mathbf{P})-\mathbf{1 0 k}$ and $\mathbf{4 0 k}$ having $\mathrm{T}_{\mathrm{g}} \mathrm{s}$ of 143 and $158^{\circ} \mathrm{C}$ respectively, and $\mathbf{P}(\mathbf{O}-\mathbf{P})-\mathbf{1 0 k}$ and 40k having $\mathrm{T}_{\mathrm{g}} \mathrm{s}$ of 72 and $88^{\circ} \mathrm{C}$ respectively (Figures S16-S17). The decrease in $\mathrm{T}_{\mathrm{g}}$ with increasing alkyl chain length can be explained by a trend toward increased segmental motion and free volume for the longer alkyl chains. ${ }^{64}$ 

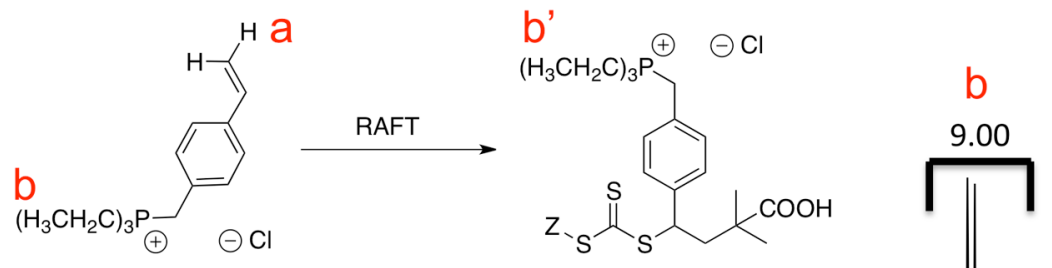

a)

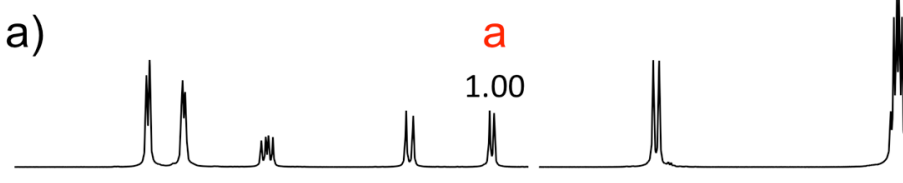

b)

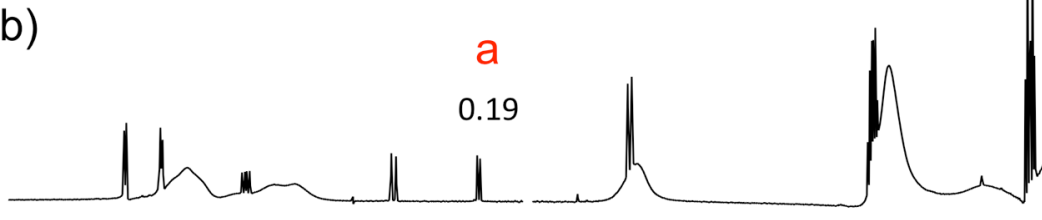

b'

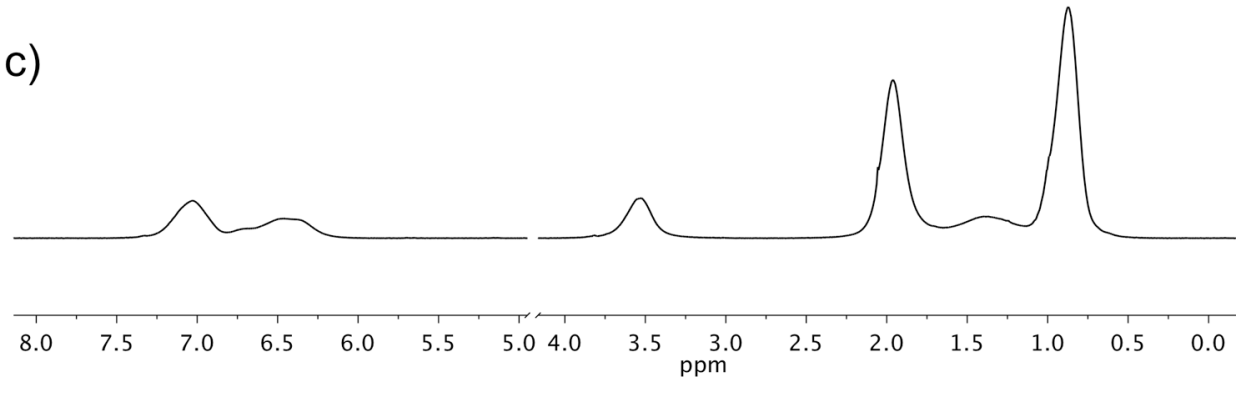

Figure 2. ${ }^{1} \mathrm{H}$ NMR spectra $\left(400 \mathrm{MHz}, \mathrm{D}_{2} \mathrm{O}\right)$ of a) The Et-P polymerization mixture prior to polymerization; b) Unpurified P(Et-P)-40k polymerization mixture at $81 \%$ conversion; c) Purified P(Et-P)-40k. Monomer conversion was determined based on the relative integrations of the vinylic hydrogen labeled at $5.25 \mathrm{ppm}$ and the peaks from $0.75-0.90 \mathrm{ppm}$ corresponding to the terminal methyl groups in the monomer b and the polymer b' that are set to a total constant integration of 9.0 throughout the polymerization. 
Table 1. Summary of the polyphosphoniums prepared for this study as well as their molar mass characteristics and thermal properties. ${ }^{\mathrm{a}}$ Measured by ${ }^{1} \mathrm{H}$ NMR spectroscopy; ${ }^{\mathrm{b}}$ Measured by UV-vis spectroscopy (error corresponds to the standard deviation on 3 measurements).

\begin{tabular}{|c|c|c|c|c|}
\hline Polymer & $\begin{array}{l}M_{\mathrm{n}} \text { based on } \\
\text { monomer } \\
\text { conversion }^{\mathrm{a}} \\
(\mathrm{kg} / \mathrm{mol})\end{array}$ & $\begin{array}{l}M_{n} \text { based on end- } \\
\text { group analysis }^{b} \\
(\mathrm{~kg} / \mathrm{mol})\end{array}$ & $\begin{array}{l}\text { Decomposition onset } \\
\text { temperature }\left(\mathrm{T}_{0},{ }^{\circ} \mathrm{C}\right)\end{array}$ & $\mathbf{T}_{\mathrm{g}}$ (onset, ${ }^{\circ} \mathrm{C}$ ) \\
\hline$P($ Et-P)-10k & 10.6 & $13.8 \pm 0.4$ & 386 & 219 \\
\hline$P(E t-P)-40 k$ & 42.5 & $44 \pm 1$ & 389 & 215 \\
\hline$P(B u-P)-10 k$ & 10.6 & $10 \pm 3$ & 368 & 143 \\
\hline$P(B u-P)-40 k$ & 41.7 & $42 \pm 1$ & 363 & 158 \\
\hline$P(O-P)-10 k$ & 10.5 & $8.4 \pm 1$ & 345 & 72 \\
\hline$P(O-P)-40 k$ & 40.0 & $32 \pm 1$ & 356 & 88 \\
\hline
\end{tabular}

\section{Preparation and characterization of polyphosphonium SIPNs}

For the preparation of SIPNs, tetra(ethylene glycol) diacrylate (TEGDA) was selected as the crosslinker because of it provides robust, flexible networks with each of $\mathbf{P}(\mathbf{E t}-\mathbf{P}), \mathbf{P}(\mathbf{B u}-\mathbf{P})$, and $\mathbf{P}(\mathbf{O}-\mathbf{P})$. The formulations were composed of TEGDA, a polyphosphonium, and 2,2-dimethoxy-2phenylacetophenone (DMPA) as the photoinitiator $\left(\lambda_{\max }=325 \mathrm{~nm}\right)$. Each of the six polyphosphoniums was incorporated at $0.1,1$, and $10 \mathrm{wt} \%$ (Table 2.). The DMPA content was fixed at $5 \mathrm{wt} \%$ and the TEGDA was added to make up the remaining percentage to $100 \%$ in terms of the dry weight. All 
formulations were diluted 2-fold with solvent to obtain homogeneous solutions, using methanol for formulations containing $\mathbf{P}(\mathbf{E t}-\mathbf{P})$ and $N, N$-dimethylformamide (DMF) for $\mathbf{P}(\mathbf{B u}-\mathbf{P})$ and $\mathbf{P}(\mathbf{O}-\mathbf{P})$. For curing, the formulations were cast on clean glass slides and spacers were used to define the thickness after another glass slide was placed on top (Figure S18). This reproducibly produced SIPNs approximately $250 \mu \mathrm{m}$ thick, with a surface area of approximately $2.25 \mathrm{~cm}^{2}$, while simultaneously enabling the polymerization to occur in an environment relatively free of oxygen, thereby reducing the rate of radical termination. This thickness and film casting method were selected to afford sufficient material for the characterization experiments described below, but other techniques such as dip coating or spin coating can be used to achieve thinner films, depending on the application. Curing was performed using a conveyor UV-curing system equipped with a mercury bulb (Figure S18).

Table 2. Summary of the composition and properties of polyphosphonium SIPNs. Each formulation contained $5 \mathrm{wt} \%$ DMPA, $0.1,1$, or $10 \mathrm{wt} \%$ polyphosphonium, and TEGDA to make up the remaining percentage. Errors are reported as the standard deviation on at least 3 measurements.

\begin{tabular}{|l|l|l|l|l|}
\hline $\begin{array}{l}\text { Formulation } \\
\text { composition }\end{array}$ & Cure \% & $\begin{array}{l}\text { Gel Content } \\
(\%)\end{array}$ & $\begin{array}{l}\text { Water contact } \\
\text { angle }\left({ }^{\circ}\right)\end{array}$ & $\begin{array}{l}\text { Charge density } \\
\left(\text { charges } / \mathrm{cm}^{2}\right) \times 10^{14}\end{array}$ \\
\hline P(Et-P)-10k $(10 \mathrm{wt} \%)$ & $82 \pm 4$ & $90 \pm 2$ & $58 \pm 1$ & $1.1 \pm 0.1$ \\
\hline P(Et-P)-10k $(1 \mathrm{wt} \%)$ & $86 \pm 1$ & $99 \pm 1$ & $45 \pm 11$ & $0.4 \pm 0.1$ \\
\hline P(Et-P)-10k $(0.1 \mathrm{wt} \%)$ & $85 \pm 1$ & $90 \pm 3$ & $47 \pm 4$ & $0.4 \pm 0.1$ \\
\hline P(Et-P)-40k $(10 \mathrm{wt} \%)$ & $85 \pm 3$ & $97 \pm 1$ & $59 \pm 1$ & $39 \pm 1$ \\
\hline P(Et-P)-40k $(1 \mathrm{wt} \%)$ & $87 \pm 3$ & $98 \pm 1$ & $48 \pm 1$ & $0.09 \pm 0.03$ \\
\hline P(Et-P)-40k $(0.1 \mathrm{wt} \%)$ & $88 \pm 1$ & $98 \pm 1$ & $48 \pm 1$ & $0.025 \pm 0.002$ \\
\hline
\end{tabular}




\begin{tabular}{|l|l|l|l|l|}
\hline P(Bu-P)-10k (10 wt\%) & $94 \pm 2$ & $88 \pm 1$ & $64 \pm 3$ & $198.5 \pm 1.3$ \\
\hline P(Bu-P)-10k (1 wt\%) & $94 \pm 2$ & $98 \pm 1$ & $59 \pm 3$ & $192.2 \pm 1.2$ \\
\hline P(Bu-P)-10k (0.1 wt\%) & $98 \pm 1$ & $95 \pm 1$ & $63 \pm 7$ & $93.1 \pm 34.6$ \\
\hline P(Bu-P)-40k (10 wt\%) & $96 \pm 1$ & $86 \pm 5$ & $61 \pm 2$ & $198.6 \pm 1.3$ \\
\hline P(Bu-P)-40k (1 wt\%) & $95 \pm 2$ & $94 \pm 2$ & $65 \pm 2$ & $147.3 \pm 0.2$ \\
\hline P(Bu-P)-40k (0.1 wt\%) & $95 \pm 1$ & $97 \pm 1$ & $59 \pm 3$ & $50.6 \pm 3.7$ \\
\hline P(O-P)-10k (10 wt\%) & $97 \pm 2$ & $96 \pm 1$ & $73 \pm 2$ & $204.4 \pm 4.0$ \\
\hline P(O-P)-10k (1 wt\%) & $98 \pm 1$ & $98 \pm 1$ & $65 \pm 6$ & $190.1 \pm 13.2$ \\
\hline P(O-P)-10k (0.1 wt\%) & $88 \pm 2$ & $98 \pm 1$ & $66 \pm 7$ & $75.7 \pm 12.8$ \\
\hline P(O-P)-40k (10 wt\%) & $91 \pm 1$ & $98 \pm 1$ & $58 \pm 2$ & $68.1 \pm 17.4$ \\
\hline P(O-P)-40k (1 wt\%) & $98 \pm 1$ & $98 \pm 1$ & $62 \pm 5$ & $135.2 \pm 13.7$ \\
\hline P(O-P)-40k (0.1 wt\%) & $97 \pm 1$ & $98 \pm 1$ & $52 \pm 8$ & $106.4 \pm 24.0$ \\
\hline
\end{tabular}

The properties of the SIPNs are summarized in Table 2. The cure percentage indicates the percentage of reacted polymerizable functional groups and was determined by ATR-FTIR spectroscopy. This was estimated based on the decrease in the height of the peak corresponding to the acrylate $\mathrm{C}=\mathrm{C}-\mathrm{H}$ bend at $810 \mathrm{~cm}^{-1}$ upon conversion from formulation to SIPN in comparison to the carbonyl $\mathrm{C}=\mathrm{O}$ peak at $1720 \mathrm{~cm}^{-1}$ as an internal standard (Figure S19). All cure percentages were above $80 \%$, although this value is likely lower then the actual percentage because although the peak height was greater than zero, no observable peak was detected (Figure S19). While the cure percentage indicates the percentage of reacted polymerizable functional groups, the gel content is a measure of the mass percentage of material incorporated into the network. These two values may differ from one 
another, as TEGDA requires the reaction of only one of its functional groups in order for it to be incorporated covalently into the network. In addition, the polyphosphonium does not have any polymerizable group that could be detected by IR spectroscopy, but could be incorporated through physical entanglements and/or by fragmentation of the terminal RAFT agent and subsequent reaction of the resulting radical-terminated polymer with the network. To assess this, SIPNs were first dried under vacuum to remove residual solvent. The dry materials were weighed, and then swelled in excess methanol (for $\mathbf{P}(\mathbf{E t}-\mathbf{P})$ ) or $\mathrm{CH}_{3} \mathrm{CN}$ (for $\mathbf{P}(\mathbf{B u}-\mathbf{P})$ and $\mathbf{P}(\mathbf{O}-\mathbf{P})$ ) to remove all monomers, oligomers, and polymers that were not incorporated into the network. They were dried and re-weighed, and the mass remaining was determined as the gel content. As shown in Table 2, all SIPNs had gel content greater than $86 \%$, with most higher than $90 \%$. There were no systematic reductions in gel content upon incorporation of increasing percentages of the polyphosphoniums.

DSC was also performed on the SIPNs in order to probe for the potential phase separation of the polyphosphoniums from the TEGDA networks. As shown in Figure 3, a TEGDA network without polyphosphonium had a $\mathrm{T}_{\mathrm{g}}$ of $25^{\circ} \mathrm{C}$. As summarized in Table 1 and Figures S16-S17, P(Et-P) and $\mathbf{P}(\mathbf{B u}-\mathbf{P})$ had clear $\mathrm{T}_{\mathrm{g}} \mathrm{s}$ of $215-219{ }^{\circ} \mathrm{C}$ and $143-158^{\circ} \mathrm{C}$ respectively, while $\mathbf{P}(\mathbf{O}-\mathbf{P})$ exhibited more subtle $\mathrm{T}_{\mathrm{g}}$ of $72-88^{\circ} \mathrm{C}$. As shown in Figure 3 for $\mathbf{P}(\mathbf{B u}-\mathbf{P})-10 \mathrm{k}(10 \mathrm{wt} \%)$ the SIPN exhibited a $\mathrm{T}_{\mathrm{g}}$ similar to that of the TEGDA alone. Similarly, no polyphosphonium $\mathrm{T}_{\mathrm{g}}$ was observed for any other $\mathbf{P}(\mathbf{B u}-\mathbf{P})$ or P(O-P) SIPN at $10 \mathrm{wt} \%$ (Figure S20). This suggests that there was no detectable phase separation of the polyphosphoniums from the TEGDA network, and that the polyphoshoniums were reasonably well dispersed in the network. Unfortunately, the P(Et-P) SIPNs could not be analyzed by this method as their degradation temperature $\left(\mathrm{T}_{\mathrm{o}} \sim 220^{\circ} \mathrm{C}\right)$ is below that of the $\mathrm{T}_{\mathrm{g}}$ of $\mathbf{P}(\mathbf{E t}-\mathbf{P})$. Clearly, the thermal stability of the network is limited by the TEGDA component, rather than the polyphosphonium as the polyphosphoniums were stable in TGA to $>380^{\circ} \mathrm{C}$. 


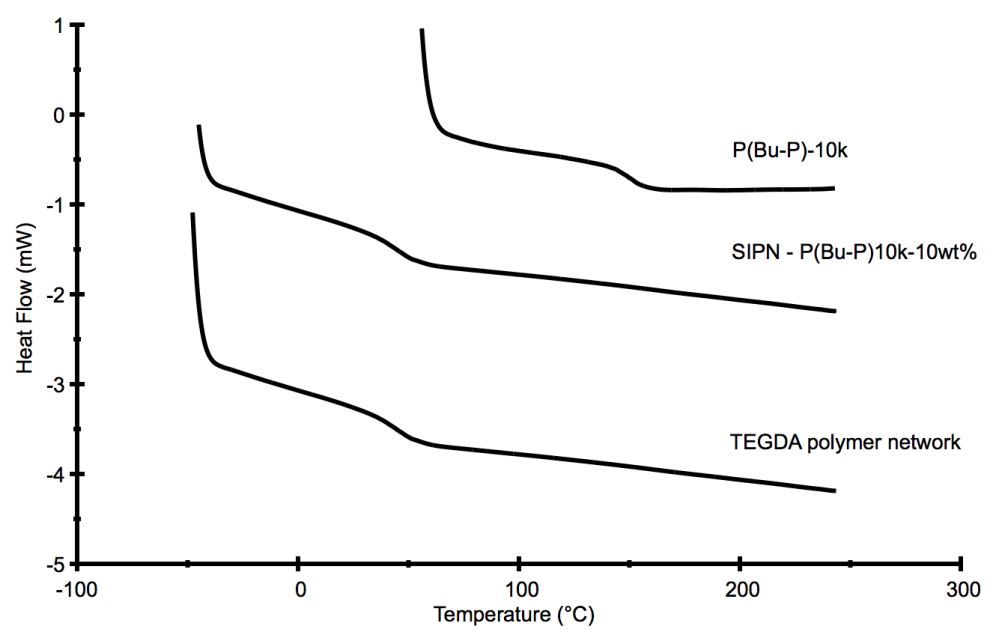

Figure 3. DSC curves for $\mathbf{P}(\mathbf{B u}-\mathbf{P})-\mathbf{1 0 k}$, an SIPN prepared using $10 \mathrm{wt} \%$ of $\mathbf{P}(\mathbf{B u}-\mathbf{P})-\mathbf{1 0 k}$, and an SIPN prepared from TEGDA without polyphosphonium. The results show that no polyphosphonium $\mathrm{T}_{\mathrm{g}}$ was detected for the SPIN, suggesting the polyphosphonium is well-dispered in the SIPN rather than phaseseparated.

It has been previously reported that high surface charge is one of the most important parameters for polycationic surfaces to exhibit high antibacterial activity. ${ }^{65}$ Specifically, a charge density of $10^{14}$ charges $/ \mathrm{cm}^{2}$ has been suggested as a minimum requirement for killing bacteria. The charge densities of the UV-cured SIPNs were evaluated by immersion of the SIPN in an aqueous solution of fluorescein dye, resulting in anion exchange with chloride anions associated with accessible phosphoniums. ${ }^{56}$ After washing to remove excess unbound fluorescein, the surfaces were immersed in a solution of the anionic surfactant, hexadecyltrimethylammonium chloride, to exchange the fluorescein back into solution. This surfactant/fluorescein solution was measured by UV-visible spectroscopy for the quantitative analysis of fluorescein. As shown in Table 2, at $10 \mathrm{wt} \%$ loading, all phosphonium SIPNs had greater than $10^{14}$ cations $/ \mathrm{cm}^{2}$. In general, the accessible surface charge increased as the polyphosphonium content was increased from 0.1 to $10 \mathrm{wt} \%$. However, there were no general trends relating the surface charge to the 
molar mass of the polyphosphonium. In comparison to our previously reported phosphonium networks prepared from an acrylate-functionalized phosphonium monomer via UV curing, ${ }^{52}$ the SIPNs prepared from $\mathbf{P}(\mathbf{B u}-\mathbf{P})$ displayed the same accessible surface charge at $1-10 \mathrm{wt} \%$ of polyphosphonium as the previous networks did at $40-50 \mathrm{wt} \%$ of phosphonium monomer. This may be attributed to the presence of long polyphosphonium chains at or near the surface, and the increased hydrophilicity and flexibility of the TEGDA relative to the previously used cross-linker tricyclo[5.2.1. $\left.0^{2,6}\right]$ decanedimethanol diacrylate, which enables swelling and penetration of fluorescein into the networks. ${ }^{30}$

While the SIPNs prepared from $\mathbf{P}(\mathbf{B u}-\mathbf{P})$ and $\mathbf{P}(\mathbf{O}-\mathbf{P})$ had similar surface charge densities, the P(Et-P) surfaces had significantly lower surface charge densities. This initially appears counterintuitive as $\mathbf{P}(\mathbf{E t}-\mathbf{P})$ is more hydrophilic, and has a higher charge density for a given molar mass or volume. However, hydrophilic surfaces have been reported to undergo hydrophobic recovery (surface reversion) to minimize their free energy. ${ }^{66}$ The hydrophilicity of $\mathbf{P ( E t - P )}$ may make it susceptible to becoming buried below the material surface, thereby reducing its accessibility. This is supported by analysis of the contact angles of the different SIPNs. SIPNs prepared at $10 \mathrm{wt} \%$ polyphosphonium, P(Et-P)-10k and P(Et-P)-40k had very similar contact angles $\left(\sim 60^{\circ}\right)$ to those prepared from $10 \mathrm{wt} \% \mathbf{P}(\mathbf{B u}-\mathbf{P})-\mathbf{1 0 k}$ and $\mathbf{P}(\mathbf{B u}-\mathbf{P})-\mathbf{4 0 k}$. The contact angle of the TEGDA matrix is very similar to these values at $\sim 55^{\circ}$. For $\mathbf{P}\left(\right.$ Et-P), the contact angle decreased to less than $50^{\circ}$ at lower loadings of 0.1 and $1 \mathrm{wt} \%$, suggesting that these surfaces may be less susceptible to hydrophobic recovery, perhaps because their lower polyphosphonium content allows them to be more densely cross-linked. An SIPN prepared with P(OP)-10k at $10 \mathrm{wt} \%$ had the highest water contact angle of $73^{\circ}$, likely due to the long alkyl chains on the polyphosphoniums. However, the SIPN prepared with P(O-P)-40k at $10 \mathrm{wt} \%$ exhibited a much lower contact angle of $58^{\circ}$. During preparation of the SIPNs, it was noted that formulations containing $\mathbf{P}(\mathbf{O}-$ 
P)-40k were the most difficult to dissolve and it is likely that during UV curing some phase separation occurred, resulting in poor incorporation of the $10 \mathrm{wt} \% \mathbf{P}(\mathbf{O}-\mathbf{P})-\mathbf{4 0 k}$ into the SIPN. This is corroborated by the relatively low surface charge for this SIPN in comparison with other $\mathbf{P}(\mathbf{O}-\mathbf{P})$ SIPNs.

The potential for the SIPNs to swell was probed by measuring the mass swelling ratios after incubation in water for $24 \mathrm{~h}$. Upon incorporation of the polyphosphoniums into the networks, the swelling increased from $4 \pm 2 \%$ for a TEGDA network to $28 \pm 2,52 \pm 6$, and $35 \pm 2 \%$ for P(Et-P)-10k (10 wt\%), P(Bu-P)-10k (10 wt\%), and P(O-P)-10k (10 wt\%) respectively. The high swelling of the $\mathbf{P}(\mathbf{B u}-\mathbf{P})$ SIPN may correlate with its high charge density and uniform incorporation into the network as suggested by the fluorescein assay and thermal analyses. To probe the potential for the surfaces of the SIPNs to reorganize over time, the phosphorus weight content was analyzed by SEM-EDX for freshly prepared and 8-month-old surfaces of P(Et-P)-10k (10 wt\%), P(Bu-P)-10k (10 wt\%), and P(O-P)-10k (10 wt\%). No significant changes in phosphorus content were observed, suggesting that network formation fixes the polyphosphoniums in place, resulting in stable materials. Any organization of the P(Et-P)-10k (10 wt\%) SIPN that serves to bury the phosphosphoniums occurred during or immediately following network formation and not over longer time periods.

\section{Antibacterial testing of the SIPNs}

Prior to antibacterial testing, the SIPNs were washed extensively $\left(\mathrm{H}_{2} \mathrm{O}\right.$ for $\mathbf{P}(\mathbf{E t}-\mathbf{P})$ and $\mathrm{CH}_{3} \mathrm{CN}$ for $\mathbf{P}(\mathbf{O}-\mathbf{P})$ and $\mathbf{P}(\mathbf{B u}-\mathbf{P}))$ to ensure that any observed activity did not arise from leachable phosphoniums but rather from the SIPN itself (Figure S21). Washed and dried SIPNs were then freshly ground into dispersible powders for testing. Antibacterial testing was performed using the standard testing method

ASTM E2149-13a,${ }^{57}$ involving the incubation of SIPNs with S. aureus (ATCC 6538) and E. coli (ATCC 29425) as representative strains of Gram-positive and Gram-negative bacteria respectively for 
1 hour at room temperature with agitation. The testing was performed at a concentration of $0.02 \mathrm{~g} / \mathrm{mL}$ of SIPN and $10^{5} \mathrm{CFUs} / \mathrm{mL}$ in the case of E. coli and $10^{6} \mathrm{CFUs} / \mathrm{mL}$ for $S$. aureus. The experiments were performed in triplicate. Based on preliminary results suggesting that $10 \mathrm{wt} \%$ polyphosphonium was required for high bacterial killing, only the SIPNs prepared from $10 \mathrm{wt} \%$ polyphosphonium were tested.

The antibacterial activity against $S$. aureus was highest for $\mathbf{P}(\mathbf{E t}-\mathbf{P})$ and $\mathbf{P}(\mathbf{B u}-\mathbf{P})$ with a $>99.9 \%$ reduction of bacterial CFUs, regardless of the molar mass of the polyphosphonium. The more hydrophobic $\mathbf{P}(\mathbf{O}-\mathbf{P})-10 k$ SIPN provided a significantly $(\mathrm{P}<0.05)$ lower, $50 \%$ reduction in $S$. aureus CFUs and the $\mathbf{P}(\mathbf{O}-\mathbf{P})-40 k$ SIPN did not provide any reduction in $S$. aureus CFUs. This decrease in antibacterial activity with increasing alkyl chain length may be attributed to several factors. First, as noted above, the $\sim 40 \mathrm{~kg} / \mathrm{mol} \mathbf{P}(\mathbf{O}-\mathbf{P})$ exhibited poor miscibility in the SIPN formulation, leading to an unexpectedly low contact angle and low charge density, suggestive of poor incorporation into the SIPN. However, the SIPN prepared from the $\sim 10 \mathrm{~kg} / \mathrm{mol} \mathbf{P}(\mathbf{O}-\mathbf{P})$ had a higher contact angle than the analogous SIPNs prepared from $\mathbf{P}(\mathbf{E t}-\mathbf{P})$ and $\mathbf{P}(\mathbf{B u}-\mathbf{P})$ and a similar surface charge density, suggesting the polyphosphonium was well-incorporated into the SIPN. Previously, a parabolic relationship between the hydrophobicity of polyphosphoniums and their abilities to kill Gram-positive bacteria has been reported. ${ }^{49}$ This arises from the complex mechanism by which phosphoniums are proposed to kill bacteria. The mechanism is proposed to involve 6 steps: (1) initial adsorption; (2) diffusion to the cytoplasmic membrane; (3) binding to the membrane; (4) disruption and disintegration of the membrane; (5) release of cytoplasmic components; and (6) death of the cell ${ }^{67}$ While increasing the hydrophobicity of the phosphonium may enhance binding to and disruption of the membrane, it may slow other steps such as the initial adsorption. This will be explored in more detail below. 

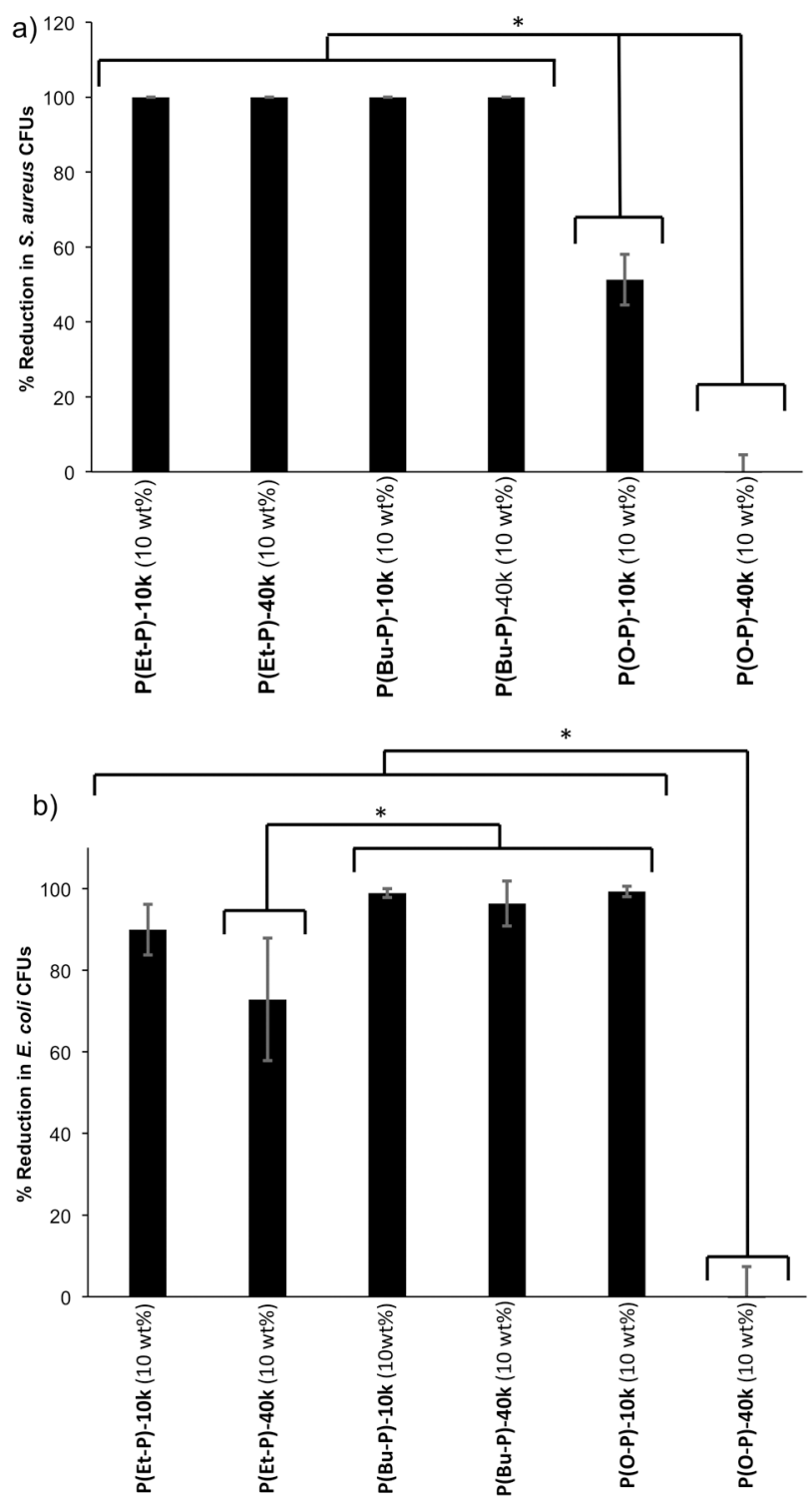

Figure 4. SIPN activity versus a) $S$. aureus and b) E. coli in the dynamic contact antibacterial test. SIPNs were tested at $0.02 \mathrm{~g} / \mathrm{mL}$ against a bacterial concentration of $10^{6} \mathrm{CFUs} / \mathrm{mL}$ of $S$. aureus and $10^{5}$ $\mathrm{CFUs} / \mathrm{mL}$ of $E$. coli for 1 hour. $0 \%$ reduction corresponds to the mean number of bacterial colonies counted when a control suspension of bacteria incubated in phosphate buffer without polymer was plated on agar, while $100 \%$ reduction corresponds to the observation of no bacterial colonies. Raw data can be found in Tables S1 and S2. * Indicates statistical significance at the $\mathrm{P}<0.05$ level as determined by an ANOVA followed by a Tukey's test. 
The ability to kill E.coli was lower than that of S. aureus for some of the SIPNs. This has also been observed for polyphosphoniums and polyammoniums previously. ${ }^{49,68}$ SIPNs prepared from P(EtP)-10k and P(Et-P)-40k reduced $E$. coli CFUs by $90 \%$ and $73 \%$ respectively, though these results were not different statistically. SIPNs containing $\mathbf{P ( B u - P ) - 1 0 k}$ and $\mathbf{P ( B u - P ) - 4 0 k}$ both exhibited high killing of $99 \%$ and $97 \%$ of $E$. coli respectively, significantly greater than P(Et-P)-40k. Unlike for $S$. aureus, the $\mathbf{P}(\mathbf{O}-\mathbf{P})-10 k$ SIPN also effectively killed $E$. coli at a level statistically greater than $\mathbf{P ( E t - P ) - ~}$ 40k. This is consistent with previous results, where increasing the phosphonium alkyl substituent chain length also increased the antibacterial efficacy against E.coli ${ }^{69}$ and can be explained by the different structures of the bacterial cell walls of Gram-negative and Gram-positive bacteria. Again, the SIPN prepared from $\mathbf{P}(\mathbf{O}-\mathbf{P})-40 k$ did not exhibit any significant activity relative to the other SIPNs, likely due to poor incorporation of the polyphosphonium into the network.

To ensure that the decrease in measured viable bacteria was not due to bacterial attachment and colonization on the SIPNs, a Live/Dead ${ }^{\circledR}$ assay was performed. This assay focused on $S$. aureus as $E$. coli didn't exhibit any detectable colonization of the surfaces under the testing conditions. A suspension containing $10^{7} \mathrm{CFUs} / \mathrm{mL}$ of $S$. aureus was deposited on the SIPNs or on a control glass slide and incubation for 24 hours. Non-adherent bacteria were rinsed off, and then the LIVE/DEAD ${ }^{\mathrm{TM}}$ cell viability assay was performed, resulting in the labeling of live bacteria on the SIPN surface in green and dead bacteria in red. As shown in Figure 5a, a high density of live bacteria was observed on the control surface. The SIPN P(Et-P)-40k had a very small number of live bacteria on the surface but a high density of dead bacteria. This suggests that the indications of the dynamic contact test that this surface was able to kill a high percentage of bacteria were valid. However, there was a tendency for dead bacteria to adhere to this surface, which may be undesirable in terms of the ability of the surface 
to kill bacteria over the longer term. SIPNs prepared from $10 \mathrm{wt} \%$ of $\mathbf{P}(\mathbf{B u}-\mathbf{P})-40 \mathbf{k}$ and $\mathbf{P}(\mathbf{O}-\mathbf{P})-\mathbf{4 0 k}$ did not have any detectable live bacteria on the surface and had much fewer dead bacteria. This suggests that increased hydrophobicity of the polyphosphonium may be beneficial for reducing fouling of the surface. It was also confirmed that the SIPNs were not leaching antibacterial phosphoniums as no zone of inhibition was observed for any of the materials in a standard zone of inhibition test (Figure S22).

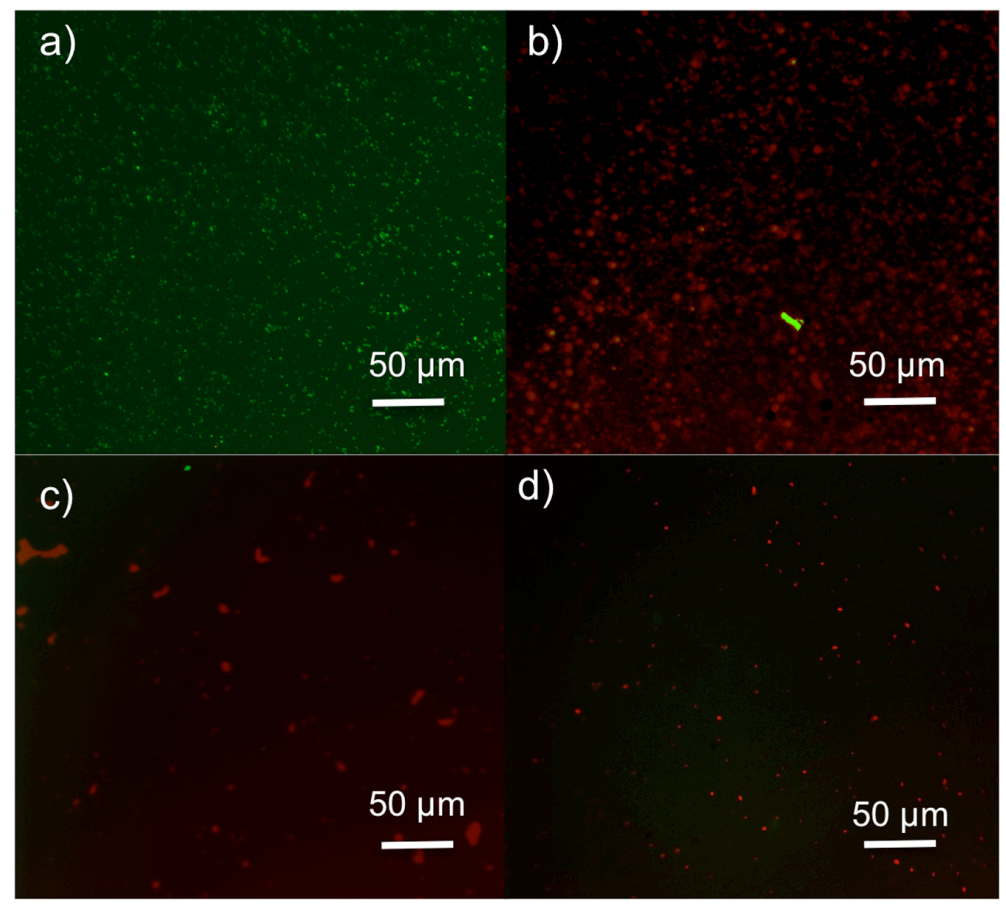

Figure 5. Control and SIPN surfaces following Live/Dead ${ }^{\circledR}$ analysis after incubation of the surfaces in a suspension of $10^{7} \mathrm{CFUs} / \mathrm{mL}$ of $S$. aureus for 24 hours: a) control glass slide; b) SIPN P(Et-P)-40k (10 wt\%); c) SIPN P(Bu-P)-40k (10 wt\%); d) SIPN P(O-P)-40k (10wt\%). Live bacteria appear green in this assay due to staining with SYTO 9, while dead bacteria appear red due to staining with propidium iodide. While live bacteria are observed on the control surfaces, decreasing numbers of dead bacteria are observed on the SIPNs with increasing phosphonium alkyl chain length.

\section{Conclusions}


Six polyphosphoniums with ethyl, butyl or octyl chains on the phosphonium and molar masses of either $\sim 10 \mathrm{~kg} / \mathrm{mol}$ or $\sim 40 \mathrm{~kg} / \mathrm{mol}$ were synthesized. Using UV curing, these polymers were incorporated into SIPNs based on TEGDA at loadings of either $0.1,1$ or $10 \mathrm{wt} \%$. High curing and gel content were achieved. Thermal analyses suggested that the polyphosphonium that was incorporated into the network quite uniformly, without phase separation. At $10 \mathrm{wt} \%$ of polyphosphonium in the formulation, all of the resulting SIPNs had greater than $10^{14}$ accessible surface charges per $\mathrm{cm}^{2}$, indicating that these SIPNs can present similar surface charge to previous polyphosphonium networks that contained much higher loadings of $\sim 50 \mathrm{wt} \%$ phosphonium monomer. However, the SIPNs prepared from P(Et-P) generally had lower surface charge densities than would be expected, which was attributed to the tendency of these hydrophilic polyphosphoniums to become buried below the surface to some extent due to the tendency of surface to minimize their free energy. The contact angles of the surfaces ranged from $45^{\circ}$ for the $\mathbf{P}(\mathbf{E t}-\mathbf{P})-\mathbf{1 0 k}$ at $1 \mathrm{wt} \%$ to $73^{\circ}$ for $\mathbf{P}(\mathbf{O}-\mathbf{P})-10 \mathbf{k}$ at $10 \mathrm{wt} \%$. On the other hand, the contact angle for $\mathbf{P}(\mathbf{O}-\mathbf{P})-\mathbf{4 0 k}$ was much lower, which was attributed to some miscibility issues that were encountered during the SIPN preparation. Other than this, no significant effects of polyphosphonium molar mass were observed. Antibacterial testing was performed on the SIPNs prepared from $10 \mathrm{wt} \%$ polyphosphonium with Gram-positive S. aureus and Gram-negative $E$. coli. All $\mathbf{P}(\mathbf{E t}-\mathbf{P})$ and $\mathbf{P}(\mathbf{B u}-\mathbf{P})$ SIPNs exhibited high activity against $S$. aureus, while the activity of the $\mathbf{P}(\mathbf{O}-\mathbf{P})-\mathbf{1 0 k}$ was somewhat lower and the $\mathbf{P}(\mathbf{O}-\mathbf{P})-\mathbf{4 0 k}$ SIPN did not kill $S$. aureus, likely due to the miscibility issue described above. On the other hand, the activities of the SIPNs against $E$. coli increased with the alkyl chain length on the phosphonium resulting in high activity for the $\mathbf{P}(\mathbf{B u}-\mathbf{P})$ and the $\mathbf{P}(\mathbf{O}-\mathbf{P})-10 k$ SIPNs. A Live/Dead $®$ assay revealed that dead bacteria tended to adhere to the $\mathbf{P}(\mathbf{E t}-$ P) SIPN surface, whereas it adhered to $\mathbf{P}(\mathbf{B u}-\mathbf{P})$ and $\mathbf{P}(\mathbf{O}-\mathbf{P})$ SIPNs to a much lesser extent. These results suggest that $\mathbf{P}(\mathbf{B u}-\mathbf{P})$ SIPNs provide the good balance of broad spectrum bacterial killing and 
anti-fouling properties. Overall, this study shows that polyphosphonium SIPNs can be prepared through a simple UV curing process and that their properties can be tuned according to the phosphonium content and phosphonium alkyl chain length. These SIPN coatings could be suitable for many different applications including high bacterial transfer objects in hospitals or public areas such as elevator buttons, door handles, railings, or beds.

\section{Acknowledgements}

The authors thank the Natural Science and Engineering Council of Canada Discovery Grant Program and the University of Western Ontario for funding this work.

\section{References}

1. Q. Chen, H. Chen, L. Zhu, and J. Zheng, J. Mater. Chem. B, 2015, 3, 3654-3676.

2. C. J. Kloxin and C. N. Bowman, Chem. Soc. Rev., 2013, 42, 7161-73.

3. S. Ligon, M. Schwentenwein, C. Gorsche, J. Stampfl, and R. Liska, Polym. Chem., 2015, 7, 257-286.

4. G. Markovic, M. Marinovic-Cincovic, V. Jovanovic, S. Samarzija-Jovanovic, and J. BudinskiSimendic, Natural Rubber Materials, The Royal Society of Chemistry, 2014.

5. L. R. Hart, S. Li, C. Sturgess, R. Wildman, J. R. Jones, and W. Hayes, ACS Appl. Mater. Interfaces, 2016, 8, 3115-3122.

6. J. Yue, P. Zhao, J. Y. Gerasimov, M. van de Lagemaat, A. Grotenhuis, M. Rustema-Abbing, H. C. van der Mei, H. J. Busscher, A. Herrmann, and Y. Ren, Adv. Funct. Mater., 2015, 25, 67566767.

7. S. Ahadian, R. B. Sadeghian, S. Salehi, S. Ostrovidov, H. Bae, M. Ramalingam, and A. 
Khademhosseini, Bioconjug. Chem., 2015, 26, 1984-2001.

8. P. Matricardi, C. Di Meo, T. Coviello, W. E. Hennink, and F. Alhaique, Adv. Drug Deliv. Rev., 2013, 65, 1172-1187.

9. J. P. Gong, Y. Katsuyama, T. Kurokawa, and Y. Osada, Adv. Mater., 2003, 15, 1155-1158.

10. T. Pascal, R. Mercier, and B. Sillion, Polymer, 1990, 31, 78-83.

11. H. S. Do, Y. J. Park, and H. J. Kim, J. Adhes. Sci. Technol., 2006, 20, 1529-1545.

12. J. W. Rumer, R. S. Ashraf, N. D. Eisenmenger, Z. Huang, I. Meager, C. B. Nielsen, B. C. Schroeder, M. L. Chabinyc, and I. McCulloch, Adv. Energy Mater., 2015, 5, 1401426. DOI: 10.1002/aenm.201401426.

13. Y. Zhang, C. Rocco, F. Karasu, L. G. J. van der Ven, R. A. T. M. van Benthem, X. Allonas, C. Croutxé-Barghorn, A. C. C. Esteves, and G. de With, Polymer, 2015, 69, 384-393.

14. A. M. Klibanov, J. Mater. Chem., 2007, 17, 2479-2482.

15. N. Yoshie, S. Saito, and N. Oya, Polymer, 2011, 52, 6074-6079.

16. B. K. Ahn, D. W. Lee, J. N. Israelachvili, and J. H. Waite, Nat. Mater., 2014, 13, 867-872.

17. S. Chen, J. Li, Y. Zhu, Z. Guo, and S. Su, J. Mater. Chem. A, 2013, 1, 15242-15246.

18. R. A. Plenderleith, C. J. Pateman, C. Rodenburg, J. W. Haycock, F. Claeyssens, C. Sammon, and S. Rimmer, Soft Matter, 2015, 11, 7567-7578.

19. L. H. Sperling, Encycl. Polym. Sci. Technol., 2004, 110-149.

20. A. S. Shaplov, D. O. Ponkratov, P. S. Vlasov, E. I. Lozinskaya, L. V. Gumileva, C. Surcin, M. Morcrette, M. Armand, P. H. Aubert, F. Vidal, and Y. S. Vygodskii, J. Mater. Chem. A, 2015, 3, $2188-2198$.

21. S. Chen, M. Liu, S. Jin, and Y. Chen, J. Appl. Polym. Sci., 2005, 98, 1720-1726.

22. W. Voit, T. Ware, and K. Gall, Polymer, 2010, 51, 3551-3559. 
23. K. M. Rao, K. S. V. K. Rao, G. Ramanjaneyulu, K. C. Rao, M. C. S. Subha, and C. Ha, J. Biomed. Mater. Res. Part A, 2013, 102, 3196-3206.

24. L. Chikh, V. Delhorbe, and O. Fichet, J. Memb. Sci., 2011, 368, 1-17.

25. S. Naficy, G. M. Spinks, and G. G. Wallace, ACS Appl. Mater. Interfaces, 2014, 6, 4109-4114.

26. Y. Sun, S. Liu, G. Du, G. Gao, and J. Fu, Chem. Commun., 2015, 51, 8512-8515.

27. C. J. Bradaric, A. Downard, C. Kennedy, A. J. Robertson, and Y. Zhou, Green Chem., 2003, 5, $143-152$.

28. B. M. Berven, R. O. Oviasuyi, R. J. Klassen, M. Idacavage, E. R. Gillies, and P. J. Ragogna, J. Polym. Sci. Part A: Polym. Chem., 2013, 51, 499-508.

29. R. Guterman, B. M. Berven, C. T. Corkery, H. Y. Nie, M. Idacavage, E. R. Gillies, and P. J. Ragogna, J. Polym. Sci. Part A: Polym. Chem., 2013, 51, 2782-2792.

30. R. Guterman, E. R. Gillies, and P. J. Ragogna, Langmuir, 2015, 31, 5181-5189.

31. R. Guterman, M. Hesari, P. Ragogna, and M. Workentin, Langmuir, 2013, 29, 6460-6466.

32. R. Guterman, E. R. Gillies, and P. J. Ragogna, Can. J. Chem., 2015, 1-24.

33. A. R. Schultz, P. M. Lambert, N. A. Chartrain, D. M. Ruohoniemi, Z. Zhang, C. Jangu, M. Zhang, C. B. Williams, and T. E. Long, ACS Macro Lett., 2014, 3, 1205-1209.

34. M. Cloutier, D. Mantovani, and F. Rosei, Trends Biotechnol., 2015, 33, 637-652.

35. X. Zhu and X. Jun Loh, Biomater. Sci., 2015, 3, 1505-1518.

36. D. Campoccia, L. Montanaro, and C. R. Arciola, Biomaterials, 2013, 34, 8533-8554.

37. S. Y. Wong, J. S. Moskowitz, J. Veselinovic, R. A. Rosario, K. Timachova, M. R. Blaisse, R. C. Fuller, A. M. Klibanov, and P. T. Hammond, J. Am. Chem. Soc., 2010, 132, 17840-17848.

38. G. L. Woo, M. W. Mittelman, and J. P. Santerre, Biomaterials, 2000, 21, 1235-1246.

39. G. L. Y. Woo, M. L. Yang, H. Q. Yin, F. Jaffer, M. W. Mittelman, and J. P. Santerre, J. Biomed. 
Mater. Res., 2002, 59, 35-45.

40. V. Sambhy, M. M. MacBride, B. R. Peterson, and A. Sen, J. Am. Chem. Soc., 2006, 128, 97989808.

41. G. Gozzelino, C. Lisanti, and S. Beneventi, Colloids Surf., A, 2013, 430, 21-28.

42. A. Muñoz-Bonilla and M. Fernández-García, Prog. Polym. Sci., 2012, 37, 281-339.

43. A. M. Klibanov, K. Lewis, C. Liao, and J. C. Tiller, Proc. Natl. Acad. Sci. U. S. A., 2001, 98, $5981-5985$.

44. S. B. Lee, R. R. Koepsel, S. W. Morley, K. Matyjaszewski, I. U. Sun, and A. J. Russell, Biomacromolecules, 2004, 5, 877.

45. R. Tang, A. Muhammad, J. Yang, and J. Nie, Polym. Adv. Technol., 2014, 25, 651-656.

46. K. Bazaka, M. V. Jacob, R. J. Crawford, and E. P. Ivanova, Acta Biomater., 2011, 7, 2015-2028.

47. A. Lotz, M. Heller, N. Dohm, P. Cierniak, K. Bender, B. Jansenb, and R. Forch, J. Mater. Chem., 2011, 22, 19455-19461.

48. S. Karamdoust, B. Yu, C. V. Bonduelle, Y. Liu, G. Davidson, G. Stojcevic, J. Yang, W. M. Lau, and E. R. Gillies, J. Mater. Chem., 2012, 22, 4881-4889.

49. A. Kanazawa, T. Ikeda, and T. Endo, J. Polym. Sci. Part A: Polym. Chem., 1993, 31, 335-343.

50. A. Guo, F. Wang, W. Lin, X. Xu, T. Tang, Y. Shen, and S. Guo, Int. J. Biol. Macromol., 2014, 67, 163-171.

51. Y. Xue, H. Xiao, and Y. Zhang, Int. J. Mol. Sci., 2015, 16, 3626-3655.

52. T. Cuthbert, R. Guterman, P. J. Ragogna, and E. R. Gillies, J. Mater. Chem. B, 2015, 3, 14741478.

53. A. Kanazawa, T. Ikeda, and T. Endo, J. Polym. Sci. Part A: Polym. Chem., 1993, 31, 14671472. 
54. N. Haridharan and R. Dhamodharan, J. Polym. Sci. Part A: Polym. Chem., 2011, 49, 1021-1032.

55. J. T. Lai, D. Filla, and R. Shea, Macromolecules, 2002, 35, 6754-6756.

56. H. Murata, R. R. Koepsel, K. Matyjaszewski, and I. J. Russell, Biomaterials, 2007, 28, 48704879.

57. ASTM Int. West Conshohocken, PA 19428-2959 United States, 2013, www.astm.org.

58. D. J. Keddie, G. Moad, E. Rizzardo, and S. H. Thang, Macromolecules, 2012, 45, 5321-5342.

59. D. J. Keddie, Chem. Soc. Rev., 2014, 43, 496-505.

60. M. Hadadpour, J. Gwyther, I. Manners, and P. J. Ragogna, Chem. Mater., 2015, 27, 3430-3440.

61. R. Wang and A. B. Lowe, J. Polym. Sci. Part A Polym. Chem., 2007, 45, 2468-2483.

62. G. Moad, E. Rizzardo, and S. H. Thang, Aust. J. Chem., 2005, 58, 379-410.

63. K. Skrabania, A. Miasnikova, A. M. Bivigou-Koumba, D. Zehm, and A. Laschewsky, Polym. Chem., 2011, 2, 2074-2083.

64. W. S. Xu and K. F. Freed, Macromolecules, 2014, 47, 6990-6997.

65. R. Kugler, O. Bouloussa, and F. Rondelez, Microbiology, 2005, 151, 1341-1348.

66. J. Kim, M. K. Chaudhury, M. J. Owen, and T. Orbeck, J. Colloid Interface Sci., 2001, 244, 200207.

67. E. R. Kenawy, S. D. Worley, and R. Broughton, Biomacromolecules, 2007, 8, 1359-1384.

68. K. A. Gibney, I. Sovadinova, A. I. Lopez, M. Urban, Z. Ridgway, G. A. Caputo, and K. Kuroda, Macromol. Biosci., 2012, 12, 1279-1289.

69. A. Kanazawa, T. Ikeda, and T. Endo, Antimicrob. Agents Chemother., 1994, 38, 945-952. 